Article

\title{
Shock Reduction through Opposing Jets-Aerodynamic Performance and Flight Stability Perspectives
}

\author{
Shagufta Rashid ${ }^{1,+}$, Fahad Nawaz ${ }^{1,+}$, Adnan Maqsood ${ }^{1, *}+\oplus$ and Rizwan Riaz ${ }^{1}$ \\ and Shuaib Salamat ${ }^{2}$ \\ 1 Research Centre for Modelling and Simulation, National University of Sciences \& Technology, \\ Islamabad 44000, Pakistan; shaguftauet@gmail.com (S.R.); fahadnawaz11@gmail.com (F.N.); \\ principal@rcms.nust.edu.pk (R.R.) \\ 2 College of Aeronautical Engineering, National University of Sciences \& Technology, \\ Islamabad 44000, Pakistan; ssalamat@aerospace.pk \\ * Correspondence: adnan@rcms.nust.edu.pk; Tel.: +92-51-9085-5734 \\ + These authors equally contributed to this manuscript as co-first author.
}

Received: 20 November 2019; Accepted: 12 December 2019; Published: 25 December 2019

\begin{abstract}
In this research paper, investigations of counter flow (opposing) jet on the aerodynamic performance, and flight stability characteristics of an airfoil with blunt leading-edge in supersonic regime are performed. Unsteady Reynolds-Averaged Navier-Stokes (URANS) based solver is used to model the flow field. The effect of angle of attack $(\alpha)$, free-stream Mach number $\left(M_{\infty}\right)$, and pressure ratio $(P R)$ on aerodynamic performance of airfoil with and without jet are compared. The results indicate that the opposing jet reduces drag from 30\% to 70\%, improves the maximum lift-to-drag ratio from 2.5 to 4.0 , and increases shock stand-off distance from $15 \%$ to $35 \%$ depending on flow conditions. The effect of opposing jet on longitudinal flight stability characteristics, studied for the first time, indicate improvement in dynamic stability coefficients $\left(C_{m_{q}}+C_{m_{\dot{\alpha}}}\right)$ at low angles of attack. It is concluded that the opposing jet can help mitigate flight disturbances in supersonic regime.
\end{abstract}

Keywords: aerodynamic performance; flow control; opposing jet; flight stability

\section{Introduction}

The typical objectives of commercial aeronautics research during the twentieth century were centered around achieving long range, high altitude and speed. Efforts in the form of Concorde and Tupolev-144 were made for supersonic commercial travels but due to technical problems, these endeavors were abandoned. Therefore, the speed of commercial aviation was curtailed to subsonic and transonic flow regimes because of multi-faceted concerns [1]. Since 2003, there is no supersonic passenger aircraft in service [2]. Supersonic flight faces multiple problems such as undesirable acoustic signature, high drag, increased aerodynamic heating and flight instabilities. The wave drag is a specific problem of a supersonic flight, which contributes more than half of the total drag and increases rapidly with increasing free stream Mach number. This increase in drag value builds up high temperature and pressure that may damage the leading edge of the blunt body and it must be prevented [3].

This motivates researchers around the globe to explore technologies that may be used to minimize the drag for blunt bodies in supersonic flow regimes. In 1950s, the opposing jet gained immense popularity in the research community due to its durability and relatively economic implementation as compared to other methods [4,5]. The jet pushes the shock-wave away from the stagnation point and develops an interface between the shock-wave and blunt body. The interface is composed of a complex flow structure that include formation of expansion and reflection waves within the jet, barrel shocks to 
cover these waves, and an enlarged vortical structure named re-circulation region [6]. The re-circulation region ahead of the blunt body plays a prominent role in the reduction of drag. The effective shock reduction through opposing jets is also dependent on flow conditions and geometric shapes $[7,8]$.

The parameters of opposing flow jets have been investigated experimentally, numerically, as well as analytically. Experimentally, researchers ascertained an encapsulation of body due to formation of bow and re-compression shocks, called as shock caps. The ejection of secondary flow field (opposing jet) opposes the free stream flow and forms a contact surface that separate these two shocks. The encapsulation due to shocks provide a protecting blanket to reduce the body temperature $[9,10]$. Opposing jet also reduces the drag. The ejection of jet distributes the pressure over the surface and generate different low pressure zones (re-circulation or dead air regions and stagnation point or leading edge pressure after ejection of jet) as shown in Figure 1a,b [11,12].

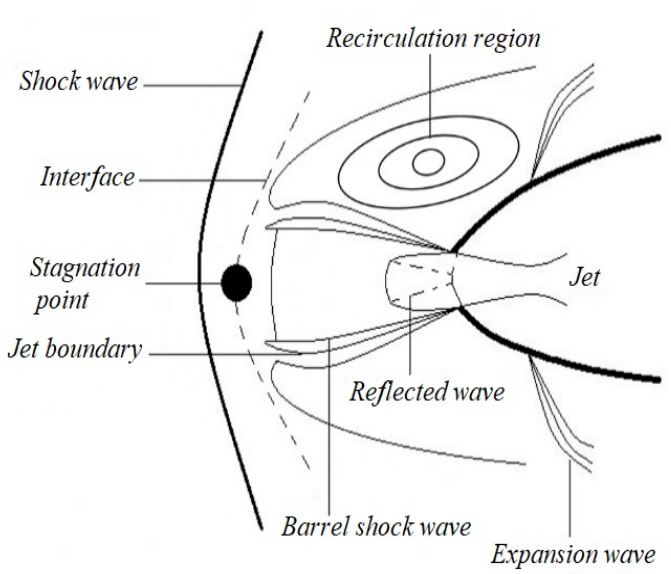

(a) Short penetration mode

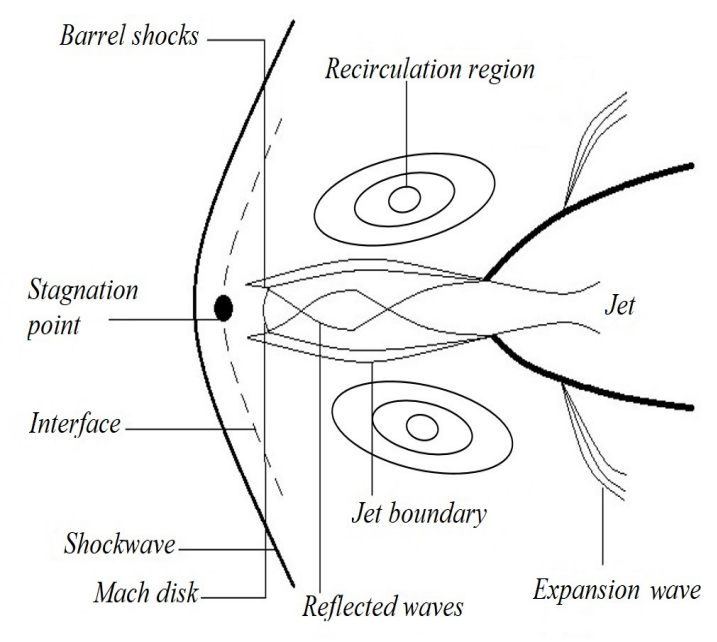

(b) Long penetration mode

Figure 1. Schematic configuration of opposing jet with two distinct modes.

Jet to body diameter ratio, shape of jet orifice and pressure ratio also effect the performance of opposing jet. The exposed front side of blunt body helps in the strength and positioning of the re-circulation regions [13]. The change in pressure ratios between free stream flow and opposing jet develop long penetration mode (LPM) and short penetration mode (SPM) [14].

The under-expanded jet (LPM) attained at low pressure ratio penetrates the bow shock and displaces it to the maximum position for the formation of conical shape [4,15]. An unstable diamond shaped pattern can be observed due to the formation of weak expansion and compression waves (reflected waves) which makes the LPM mode unstable in Figure 1b [16]. The size of re-circulation regions in $L P M$ mode are thinner and remain at the leading edge of the blunt body to cover the jet boundary. The displaced shock-wave reattaches to the surface of blunt body after passing over the re-circulation region and shows changes in pressure $[17,18]$. These changes are named turning shock-waves. A similar kind of trend is observed in SPM mode, which manifests at higher pressure ratios. The size and positioning of re-circulation regions are different than the LPM mode. Re-circulation regions are enlarged in width and placed at some distance from the vicinity of opposing jet. The reattachment of shockwave also triggers similar turning shock-waves due to change in pressure regions (upstream and downstream pressure differences due to shock-wave) as shown in Figure 1a [19].

Analytical models provide the theoretical basis of opposing jet for the mitigation of shock-wave adverse effects. Finley [20] developed an analytical model of jet flow-field, which primarily predicted the opposing force coefficient $\left(C_{F}\right)$ of jet. Later on, researchers called this force coefficient static pressure of jet. The pressure ratio of jet and body was controlled by using the concept of jet exit Mach number (Mj). Numerically it was found that the interface at front of Mach disc is blunt for large PR values 
(due to decrease in Mach of jet) as shown in Figure 1a. The simulated result suggested that the Mach disk of unstable mode is not clearly visible (due to absence of barrel shocks). The increase in free stream Mach (due to increase in pressure ratio) convert an unstable LPM into stable SPM.

The development of opposing jet technology led researchers to study various other aspects such as effect of different jet ejection materials (water, gases and plasma). By injection of cold vaporized water in airflow, drag reduced by up to $50 \%$ at the cost of very high pressure ratio [21]. Therefore, instead of using vaporized water, different gases $\left(\mathrm{He}, \mathrm{H}_{2}, \mathrm{CO}_{2}\right.$ and $\left.\mathrm{N}_{2}\right)$ were used to investigate the reduction of drag $[10,22]$. Helium $(\mathrm{He})$ is found to have better performance for drag reduction as it is lighter and inert gas (as compared to $\mathrm{CO}_{2}$ and $\mathrm{N}_{2}$ ) [23]. Although $\mathrm{H}_{2}$ is lightest, its reactive property can cause increase in heat transfer to the body [24]. A similar methodology was adopted by Fomin [25], in which plasma materials were used to reduce the shock. To get much better results for drag reduction [26], combination of passive (spike) and active (opposing jet) were tested [27-29].

The active and passive combination of flow control technologies on blunt bodies attain some additional factors (separated re-circulation regions) which produce unsteadiness in the flow and effects the stability of body. The ejection of jet reduces the unsteadiness in the flow by displacing the separation region and vortices on the surface of blunt body and stabilize the flow. Previously, researchers used wind tunnel tests [30-36], empirical and computational fluid dynamics (CFD) tools for the prediction of stability behavior. Empirical methods like DATCOM and ESDU were developed for the correct prediction of stability derivatives [37]. These methods were fast enough for the wind tunnel tests. However, these methodologies do not model the active flow control features. Therefore, a numerical approach like CFD can be used for the capturing the contributions of flow control techniques to stability characteristics $[38,39]$.

Studies conducted to date indicate that extensive investigations have been performed on the use of the opposing jet technique for the reduction of drag and heat transfer from the surface of body. However, nearly all work includes blunt bodies (like sphere, cylinder, truncated cone or aeroshells) for the ejection of jet. A limited work exists in which elliptical bodies (airfoil shaped) were used for the reduction of drag using flow control techniques, especially opposing jet [5]. For a supersonic configuration, such as Unmanned Combat Air Vehicle, a long spike or fuselage ahead of the wings will reduce its stealth features. Therefore, usage of opposing jets should be tested on the wing geometries as well. In this research, the effect of opposing jet on overall aerodynamic performance and the flight stability characteristics of a two-dimensional wing is explored. Specifically, the interaction of opposing jet with the supersonic free-stream flow is investigated using a numerical approach. The purpose is to reduce the drag from the surface of airfoil (NACA 0012) and to improve the understanding of some fundamental phenomena like effects of pressure ratios, free stream flow Mach number and their combined effects with increasing angle of attack. These phenomena affect the ejection of opposing jet and stability parameters of airfoil. The stability derivatives (statically and dynamically) are calculated using a reduced frequency approach. It is pertinent to mention that the effects of acoustic and heating are not considered in this study.

The problem formulation and validation cases are briefly presented in Section 2 . The detailed results are discussed in Section 3, which include the influence of free stream Mach number on the ejection of opposing jet in accordance with its required PR. The next section entails the effect of angle of attack on the opposing jet and its stability during perturbation. At the end, concluding remarks are presented in Section 5.

\section{Problem Formulation}

The computational setup is created by using two dimensional Unsteady Reynolds Averaged Navier Stokes (URANS) and turbulence model equations. A density based implicit solver is used as it works effectively for supersonic flows. The validation process for all geometries $(a, b$ and $c)$ (as shown in Figure 2a) followed in this research, is a three-step procedure. Like Itsariyapinyo [40], a similar grid formation strategy is adopted for all three validation steps as shown in Figure $2 b$. In the first 
step, experimental findings of Graham [41] are used to validate the aerodynamic characteristics and flow-field around a bi-convex airfoil with blunt leading edge. The second step include assessment of computational setup for adequate modeling of the opposing jet. The experimental results of Eugene [5] are reproduced numerically for with and without jet scenarios around elliptical body in supersonic regime. Finally, in the third step, experimental results of Landon and Davis [42] are compared with the computational setup to capture the dynamic stability characteristics.

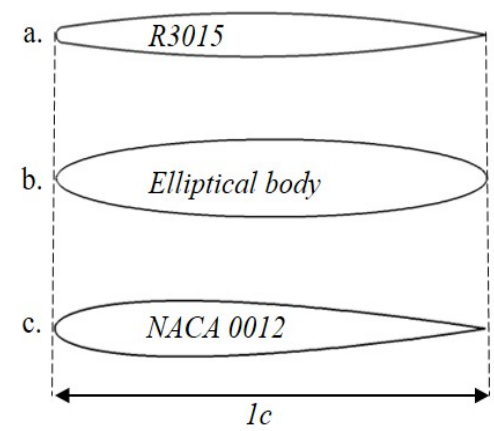

(a) Geometric illustration of all airfoils

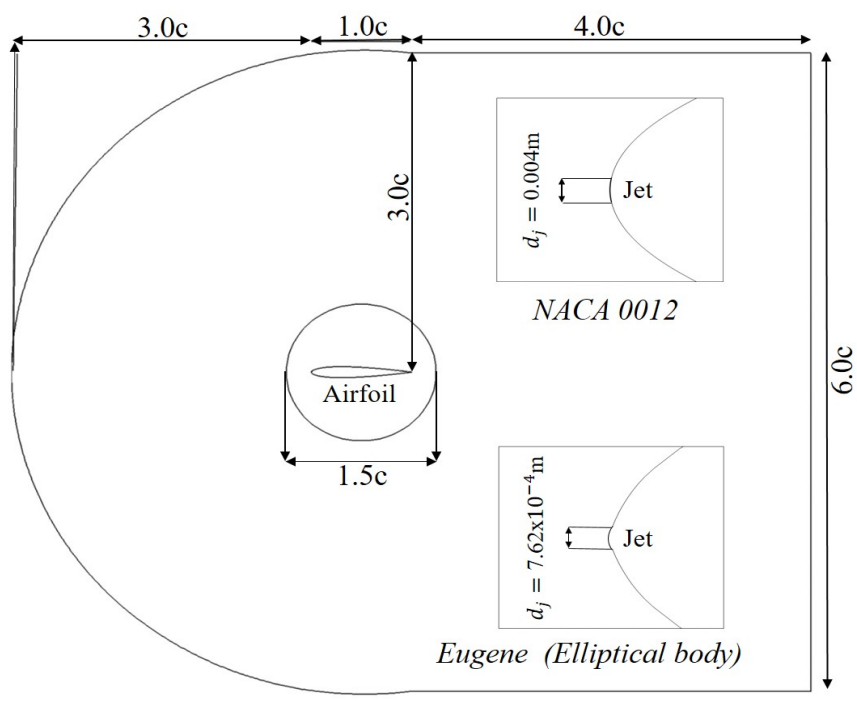

(b) Schematic view of flow domain

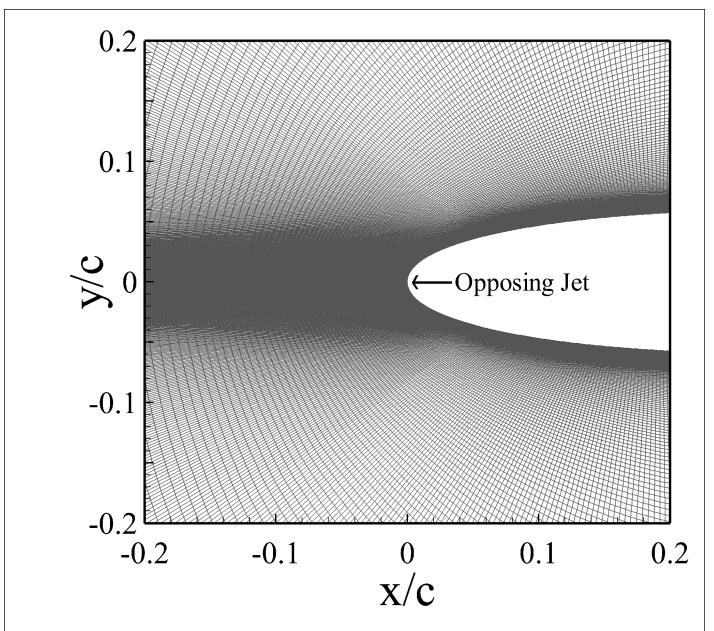

(d) In vicinity of jet

(c) Meshing topology and boundary conditions around flow domain

Figure 2. Numerical grid distribution with boundary conditions.

\subsection{Computational Setup}

In this research, NACA 0012 airfoil is selected as a reference aerodynamic surface. The airfoil has a blunt leading edge and moderate thickness to chord ratio. Moreover, it is one of the most generic airfoil shapes studied in aerodynamic literature. The airfoil has $1 \mathrm{~m}$ chord with $0.004 \mathrm{~m}$ jet orifice at leading edge (Figure 2a). 
A fully structured two-dimensional mesh was generated. The boundary layer resolution was made such that $Y^{+}$is less than one on the surface. Pressure inlet (jet), pressure outlet (static pressure at outlet) and the pressure far field (to model free-stream compressible flow up to an optimum distance) boundary conditions were selected for numerical analysis. Isentropic relations, as in Equation (1), were used to calculate the static pressure and temperature $\left(P_{\infty}, T_{\infty}\right)$ at sea level stagnation conditions $\left(P_{0_{\infty}}, T_{0_{\infty}}\right)$ [12].

$$
\frac{P_{o_{\infty}}}{P_{\infty}}=\left[1+\frac{\gamma-1}{\gamma} M^{2}\right]^{\frac{\gamma}{\gamma-1}} \quad ; \quad \frac{T_{D_{\infty}}}{T_{\infty}}=\left[1+\frac{\gamma-1}{\gamma} M^{2}\right],
$$

where $\gamma$ is the specific heat ratio. The discretized domain used for all simulations is shown in Figure 2c,d.

The compressible flow around the airfoil is simulated by using ANSYS ${ }^{\circledR}$ FLUENT. Two dimensional Unsteady Reynolds Averaged Navier Stokes (URANS) and turbulence model equations were solved using a density based implicit solver, as it works effectively for supersonic flows. The ideal gas law was used to model the flow properties in the far field. However, the viscosity of air was defined by Sutherland's viscosity law to capture the complex flow features like shock wave and re-circulation regions accurately. The $k-\omega S S T$ turbulence model was used to calculate the complex flow field which is expressed as

$$
\begin{gathered}
\frac{\partial(\rho k)}{\partial t}+\operatorname{div}(\rho k V)=\operatorname{div}\left(\mu+\frac{\mu_{t}}{\sigma_{k}} \operatorname{grad}(k)\right)+P_{k}-\beta^{*} \\
\frac{\partial(\rho \omega)}{\partial t}+\operatorname{div}(\rho \omega V)=\operatorname{div}\left(\mu+\frac{\mu_{t}}{\sigma_{\omega_{1}}} \operatorname{grad}(\omega)\right)+\gamma_{2}\left(2 \mu_{t} S_{i j} S_{i j}-\frac{2}{3} \rho k \frac{\partial U_{i}}{\partial x_{j}} \delta_{i j}\right)-\beta_{1} \rho \omega^{2}+A_{1},
\end{gathered}
$$

however, $\rho$ is density, $\omega$ is specific turbulent dissipation rate and $k$ is the turbulence kinetic energy. Where $A_{1}$ in Equation (3) represents the blending function $F_{1}$ which ensures the smooth transition between the $k-\omega$ and $k-\epsilon$. This transition can be expressed in Equation (4) as

$$
A_{1}=2\left(1-F_{1}\right) \rho \sigma_{\omega_{2}} \frac{1}{\omega} \frac{\partial k}{\partial x_{j}} \frac{\partial \omega}{\partial x_{j}} .
$$

The value of blending function $\left(F_{1}\right)$ becomes one near wall but at far position its value become zero. The building of turbulence in stagnation regions is prevented by the implementation of production limiter $\left(P_{k}\right)$. So, the generation of turbulent viscosity can be expressed as

$$
\mu_{t}=\frac{\alpha_{1} \rho k}{\max \left(\alpha_{1} \omega S F_{2}\right)},
$$

where $F_{2}$ is a second blending function with strain rate, $S$. This model was proved to be superior as it was a combined version of $k-\omega$ (for the inner boundary layer) and $k-\epsilon$ (for the outer region and outside of boundary layer). The models switch for prediction of far field flow characteristic. For the boundary layer (SST inner), constants are defined as

$$
\begin{gathered}
\sigma_{k_{1}}=0.85, \sigma_{\omega_{1}}=0.50, \alpha_{1}=0.31, \beta_{1}=0.0750, \beta^{*}=0.09, k=0.41, \\
\gamma_{1}=\beta_{1} / \beta^{*}-\sigma_{\omega_{1}} K^{2} / \sqrt{\beta^{*}}
\end{gathered}
$$

However, the constant values for outside of boundary layer (standard $k-\epsilon$ ) are represented as

$$
\begin{gathered}
\sigma_{k_{2}}=1.0, \sigma_{\omega_{2}}=0.856, \beta_{2}=0.0828, \beta^{*}=0.09, k=0.41, \\
\gamma_{2}=\beta_{2} / \beta^{*}-\sigma_{\omega_{2}} K^{2} / \sqrt{\beta^{*}}
\end{gathered}
$$


For further details about blending functions $\left(F_{1}, F_{2}\right)$, production limiter $\left(P_{k}\right)$ and SST turbulence model constants (for inside and outside of boundary layer), readers are referred to Reference [43].

\subsection{Validation of Computational Setup}

The test cases used for validation of computational setup ahead use same boundary conditions, parameters for grid generation, flow solver and turbulence model.

\subsubsection{Validation of Supersonic Airfoil with Blunt Leading-Edge}

The experimental data generated by Graham [41] on bi-convex airfoil (R3015) is validated numerically. The airfoil of $0.254 \mathrm{~m}$ chord length was cut at $15 \%$ from the leading edge to make it blunt Figure 3. The flow conditions included Reynolds number of $5 \times 10^{6}$, angle of attack of $2^{\circ}$, and Mach number of 1.4. The blunt-shaped airfoil is modeled and simulated using the computational setup mentioned above. The comparison of pressure coefficient between our numerical and experimental data show decent agreement in Figure 3. A small pressure drop at point $C$ is observed due to over-expansion. Similarly, a negligible rise in the pressure near trailing edge (point B) is still within the bounds.

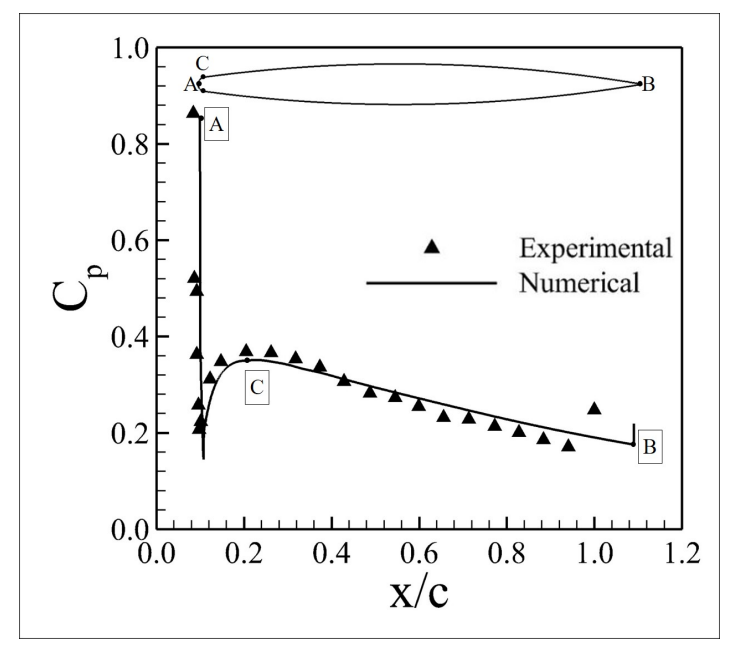

Figure 3. Surface Pressure Comparison and geometric configuration of R3015 airfoils.

\subsubsection{Modeling of Opposing Jet Flows}

The analysis of with and without opposing jet at supersonic flow regime was carried out using elliptical shaped body with the chord length of $0.1524 \mathrm{~m}$ (6 in) [5]. The free stream flow is at Mach number 1.62 with Reynolds number of $7.66 \times 10^{6}$. The opposing jet is ejected from the nozzle of diameter $0.000762 \mathrm{~m}(0.03 \mathrm{in})$ at a Mach number of one and its thrust coefficient $\left(C_{T}\right)$ was -0.0156 .

The thrust coefficient for without jet case is zero $\left(C_{T}=0\right)$. The comparison of the pressure coefficient in Figure 4a shows that our computational setup generated close agreement with the experimental data. In a similar manner, the changes in the coefficient of pressure due to the ejection of opposing jet is validated with the experimental data as illustrated from Figure $4 \mathrm{~b}$. 


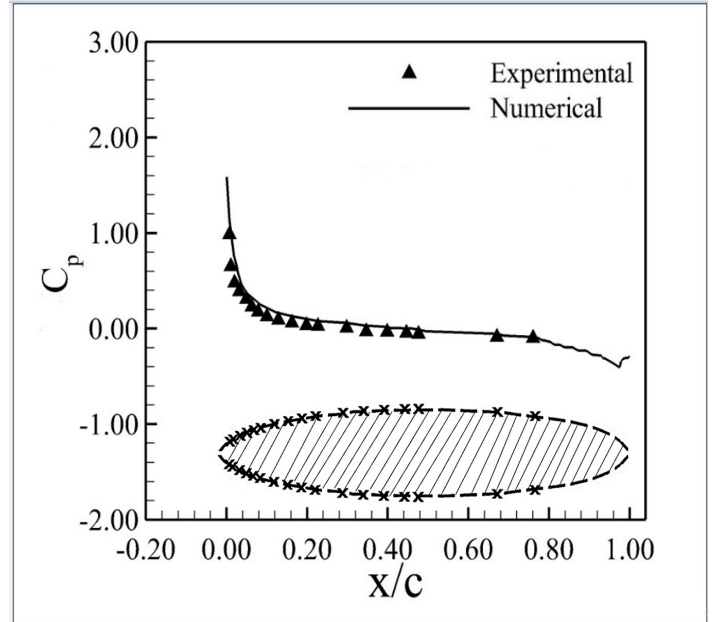

(a) Airfoil without opposing jet

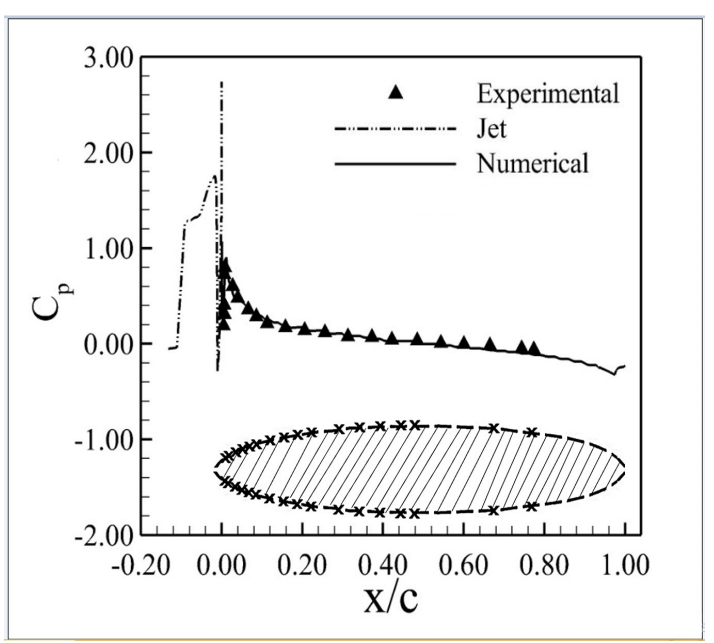

(b) Airfoil with opposing jet

Figure 4. Validation of $C_{p}$ for with and without jet case over elliptical body.

\subsubsection{Problem Setup for NACA 0012}

After validating the computational setup, NACA 0012 airfoil, considered in this study, is analyzed in transonic flow regime at free stream Mach number of 0.86 and Reynolds number of $\left(9 \times 10^{6}\right)$. The numerical results of $C_{p}$, compared with experimental data of Harris [44] shows excellent agreement in Figure 5a. Parameters like grid sizing, operating conditions and geometric accuracy might have contributed in the small variations of results. The obtained numerical result shows a similar trend as in experimental values.



(a)

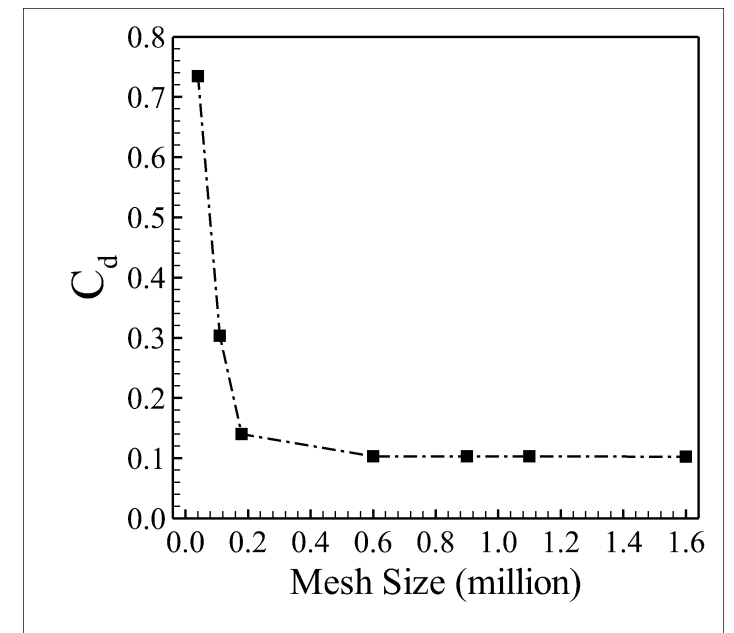

(b)

Figure 5. Comparison of pressure distribution and grid independence study of without jet case.

To attain the best agreement between the numerical and experimental data, different grid sizes were used for the analysis. The coefficient of drag ceases to vary after 0.6 mil (Figure $5 b$ ) grid. Hence, mesh with 0.6 mil was used for further analysis of opposing jet ejection and to calculate stability parameters. 


\subsubsection{Validation of Stability Cases}

In this research, the longitudinal pitch damping derivatives of NACA-0012 airfoil (with and without opposing jet) were calculated by selecting suitable parameters such as amplitude of oscillation $\left(\alpha_{A}\right)$, mean angles of attack $\left(\alpha_{\infty}\right)$ and reduced frequency $(\mathrm{k})$. The pivot point of rotation for NACA 0012 is at half of the chord (0.5c) of an airfoil for calculation of lift, drag and moment coefficients which calculate the pitch damping derivatives. The force and moment coefficients against time at different angles of attack were computed. The sinusoidal pitching motion of airfoil was achieved by applying forced pitch oscillation. A user defined function $(U D F)$ generated the oscillatory motion. A circular domain was formed around the airfoil as an interface in Figure $2 \mathrm{c}$ and oscillates against its angular frequencies. The pitching oscillation and sinusoidal motion at different angles of attack, can be related as:

$$
\begin{gathered}
\alpha(t)=\alpha_{o}+\alpha_{A} \sin (\omega t) \\
\dot{\alpha}(t)=\dot{\alpha}_{A} \omega \cos (\omega t),
\end{gathered}
$$

where $\alpha_{o}$ is the mean angle of attack while $\alpha_{A}$ is oscillatory amplitude and $\omega$ is the angular frequency. The reduced frequency $\left(k_{c}\right)$ approach builds a relationship between the angular frequency $(\omega)$ and free stream velocity $(V)$. The forced pitching oscillatory motion (sinusoidal motion) of airfoil continuously change the free stream flow angle that brings the dynamic change in the moment coefficient of airfoil. Using the Taylor expansion [45], the moment coefficient can be expanded as:

$$
C_{m}(t)=C_{m_{0}}+C_{m_{\alpha}} \alpha(t)+C_{m_{\dot{\alpha}}} \dot{\alpha} \frac{c}{2 V_{\infty}}+C_{m_{q}} q \frac{c}{2 V_{\infty}}+C_{m_{\ddot{\alpha}}} \ddot{\alpha} \frac{c}{2 V_{\infty}}+\cdots,
$$

neglecting higher order derivatives, Equation (8) will reduce to

$$
C_{m}(t)=C_{m_{o}}+C_{m_{\alpha}} \alpha(t)+C_{m_{\dot{\alpha}}} \dot{\alpha} \frac{c}{2 V_{\infty}}+C_{m_{q}} q \frac{c}{2 V_{\infty}}
$$

or

$$
C_{m}=C_{m_{o}}+C_{m_{\alpha}} \alpha+C_{m_{\dot{\alpha}}} \bar{\alpha}+C_{m_{q}} \bar{q}
$$

as $\bar{q}=\frac{q c}{2 V_{\infty}}$ and $\bar{\alpha}=\frac{\dot{\alpha} c}{2 V_{\infty}}$. So, Equation (10) becomes

$$
\left(C_{m_{\bar{\alpha}}} \overline{\dot{\alpha}}+C_{m_{\bar{q}}} \bar{q}\right)=C_{m}-\left(C_{m_{o}}+C_{m_{\alpha}} \alpha\right),
$$

where $C_{m_{\alpha}}$ and $\left(C_{m_{\dot{\alpha}}}+C_{m_{q}}\right)$ express the static and dynamic stability parameters for airfoil respectively. The values of normal force coefficient $\left(C_{n}\right)$ over the range of angle of attack show a close agreement with experimental data [42] (having Mach number 0.57 and Reynolds number of $4 \times 10^{6}$ for static case) as shown in Figure 6a. However, Figure $6 \mathrm{~b}$ shows superimposed numerical and experimental results for dynamic analysis (perturbed airfoil) by the comparison of moment coefficient $\left(C_{m}\right)$ at range of angles of attack. 


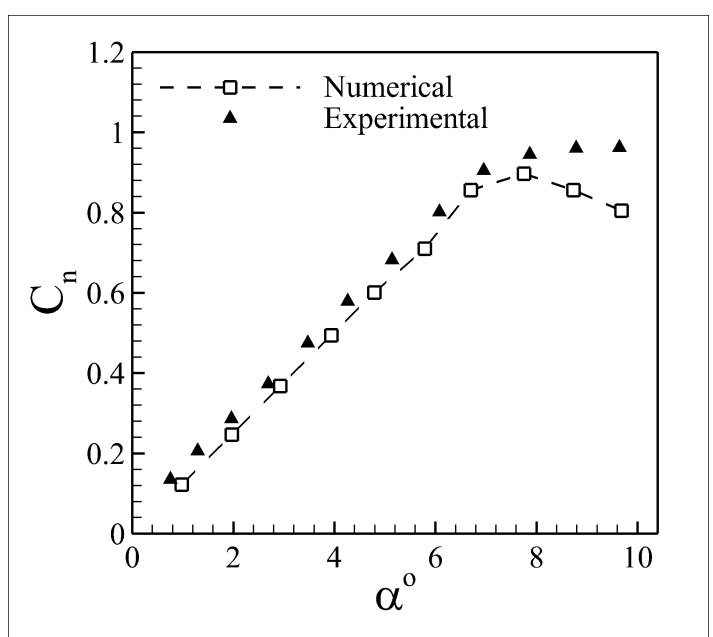

(a) $C_{n}$ along static angles of attack

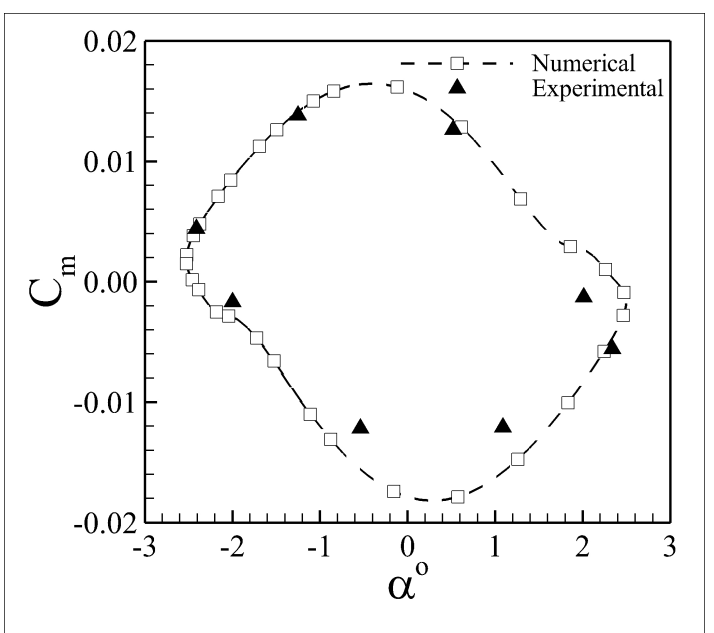

(b) Pitch damping coefficient $\left(C_{m}\right)$ long angles of attack

Figure 6. Comparison of stability derivatives with experimental data.

\section{Flow Physics of Opposing Jet}

In supersonic flow regime, the most significant feature of blunt shape airfoil is formation of bow shock-wave. This work emphasizes on the alleviation of drag by implementing the opposing jet on the leading edge of airfoil. Variation in the angle of attack, pressure ratio, and Mach number is analyzed in detail such that effective shock reduction can be quantified.

\subsection{Influence of Mach Number}

Free stream Mach is an important variable which effects the jet flow structure. A significant amount of drag reduction (up to $70 \%$ ) is demonstrated in Figure $7 \mathrm{~d}$. The percentage of reduction in drag coefficient $\left(C_{d}\right)$ improves with the increase in free stream Mach number $\left(M_{\infty}=1.4\right.$ to 3.0). Pressure ratio, $P R$ of 1.8 and Mach of jet, $M_{j}$, equal to one were used to displace the shock wave from the nose of airfoil which primarily helps in the reduction of drag coefficient. However, the effectiveness of opposing jet at these PR and $M_{j}$ decreases beyond $M_{\infty}=2.5$ as shown in Figure $7 \mathrm{~d}$.

The Mach contours and the variation of pressure at stagnation point ( 0 in $x$-axis) and surface of airfoil (with and without jet) with the increase in free stream Mach number is illustrated in Figure 8a-d. The comparison of Mach contours in Figure 8a-d clearly depicts that the smaller PR ratio is required at higher free stream Mach number to get the visible Mach disc. Fujita [46] also suggested that the increase in the free stream Mach number strengthens the bow shock and, as a result, the total pressure behind the shock decreases. The depletion in total pressure behind the shock minimize the pressure in the recirculating region so that the static pressure ratio of the jet enhances (at $M_{\infty}=2 \& M_{\infty}=3$ ), where the pressure behind the shock is considerably low.

$M_{\infty}$ at 1.4 and 1.8 , shows significantly higher drag. As a result, unstable flow structure was formed thereby exhibiting inferior performance of jet. At $M_{\infty}=2$, the jet attains the SPM mode with visible Mach disc and appropriate re-circulation region as well as reduced drag coefficient. But at $M_{\infty}$ $=3$, the opposing jet seems to be more under-expanded as the Mach disc did not maintain its shape.

In Figure $8 a-d$, the decrease in pressure values due the effects of counter flow jet at the stagnation point of airfoil are plotted. The stagnation point is displaced by means of opposing jet to an optimal distance from the leading edge of airfoil and creates a shock stand-off distance to reduce the drag. However, the graphical comparison of with and without jet raise a point which presumes that there was a sudden rise in pressure after the displacement of shock-wave.

The re-circulation region collapses near $(x / c=0.02)$ and produce turning shocks along the surface of airfoil [20]. The abrupt change in pressure values take place after the turning shocks as shown in 
Figure $7 \mathrm{~b}$ and coalesce along the surface of airfoil. Similarly, these turning shocks are of compressive nature before maximum thickness position and expansive afterwards for no jet case as shown in Figure 7a. However the re-circulation region destroyed and evolved a new free stream boundary layer for different values of $M_{\infty}$. This reattachment of free stream flow was another reason for the generation of turning shocks and increase in pressure. The hatched region in Figure $7 \mathrm{c}$ explains the difference of pressure between with and without jet curves; which were disturbed due to the generation of turning shocks.

In the similar scenario by increasing the $M_{\infty}$, pressure over surface of airfoil continuously decreases as depicted from Figure $7 \mathrm{~d}$. The main reason is movement of barrel shocks along the free stream and spreading of re-circulation region (dead-air region) over airfoil surface. So, it significantly decreases the force factors such as drag.

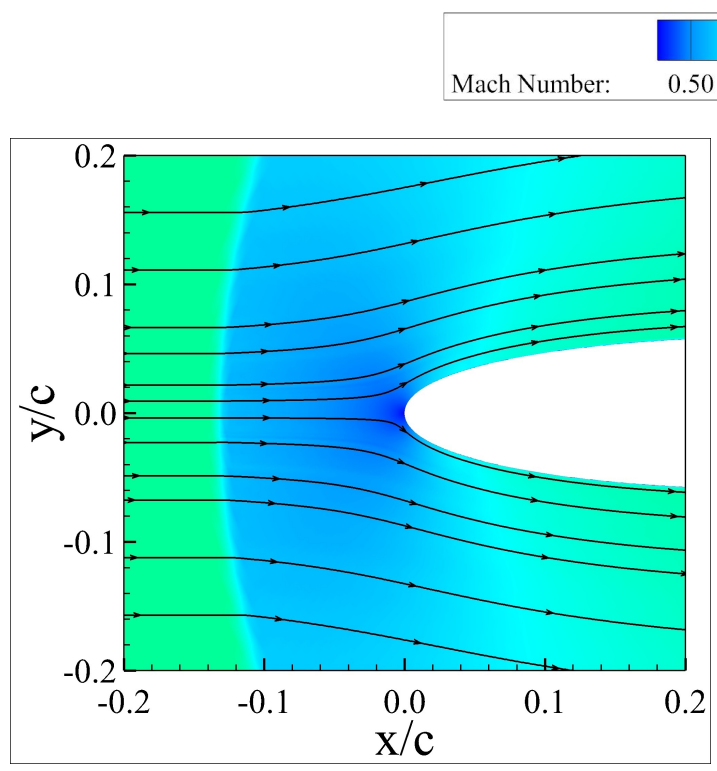

(a) Without jet

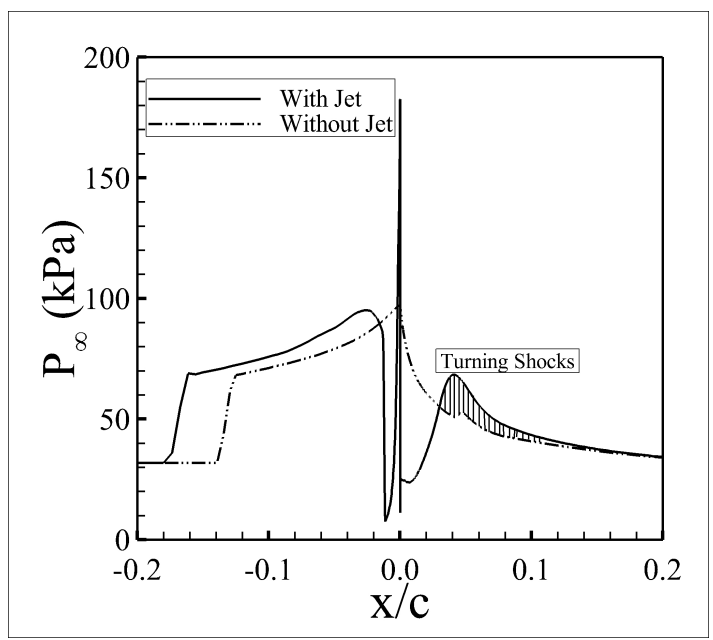

(c) Rise in Pressure due to turning shock

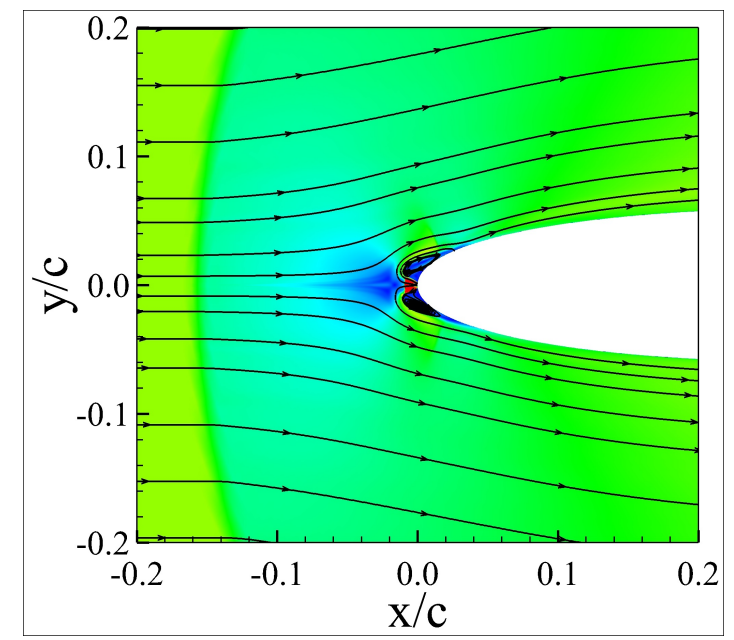

(b) With jet

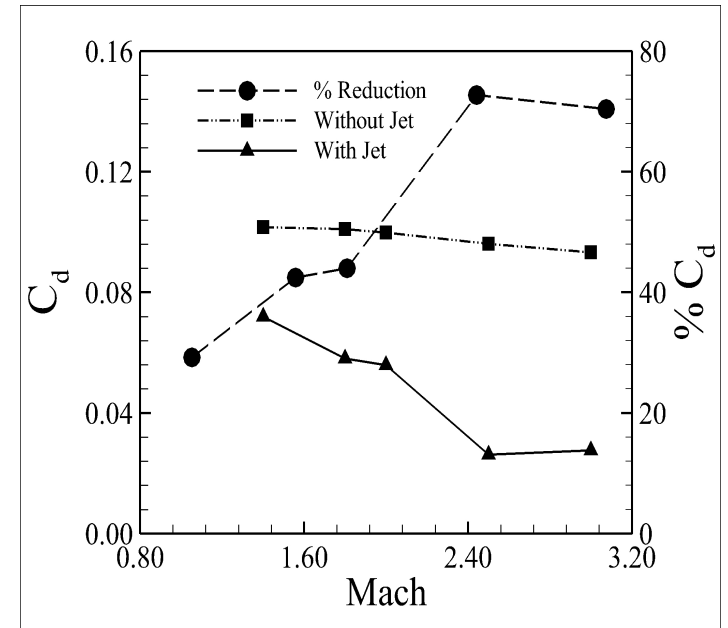

(d) Percentage reduction of drag with increasing $M_{\infty}$

Figure 7. Comparison of stream lines for Mach contours between with and without jet case. 


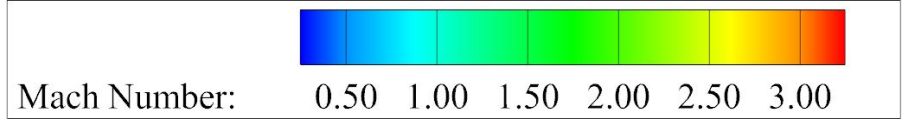
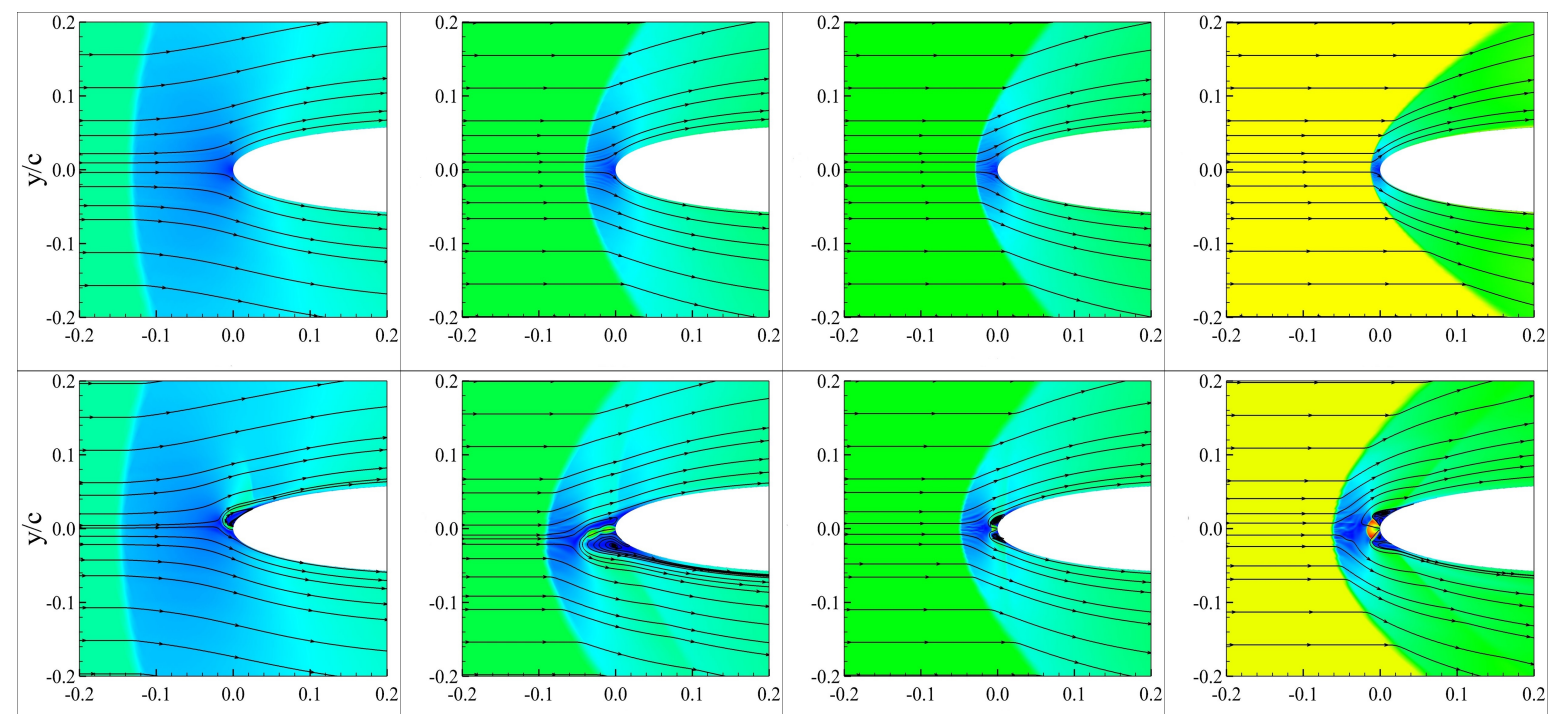

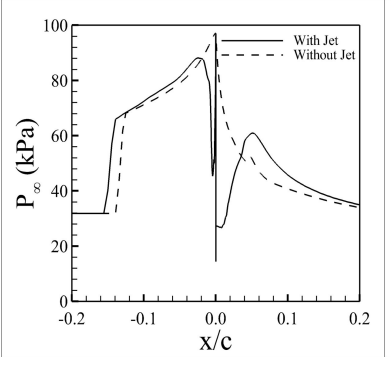

(a) $M_{\infty}=1.4$

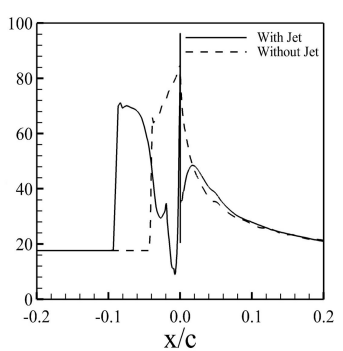

(b) $M_{\infty}=1.8$

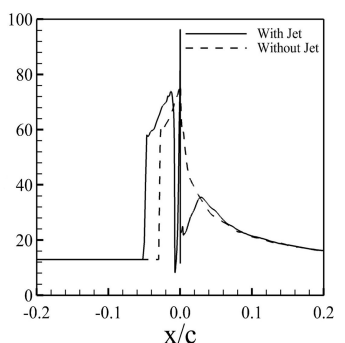

(c) $M_{\infty}=2.0$

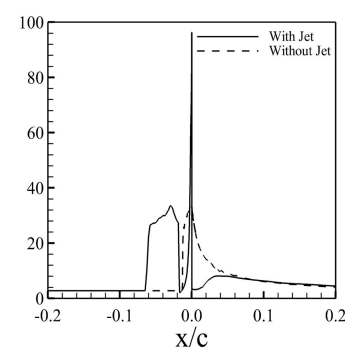

(d) $M_{\infty}=3.0$

Figure 8. Comparison of stream lines for Mach contours with constant $P R=1: 8, M_{j}=1$ and also includes the changes in pressure with increasing Mach number.

\subsection{Pressure Ratio Effects}

The flow field in the vicinity of leading edge is significantly governed by pressure ratio. The impact of opposing jet on flow field and drag was analyzed for different values of pressure ratios (0.8-4.0) at $M_{\infty}=1.4$ and $M_{j}=1$. The variation in pressure ratio (PR) generate two distinct flow modes, LPM and SPM. LPM, unsteady and undesirable, exists at low PR values. SPM, steady and desirable, exist at higher PR, which is more beneficial for drag and heat flux reduction [47]. In between the oscillating/unstable LPM and stable SPM, a transition regime is also observed.

The re-circulation region generated as a result of opposing jet is illustrated in Figure 9c. Interestingly, the pressure on the upper surface of airfoil remains same (while, moving towards the trailing edge) for with and without jet at zero degree angle of attack (as displayed in Figure 9a,b. Points A, B, and C in Figure 9d explain the peak pressure values for flow countered with and without jet. Point $B$ is the stagnation point for no jet case that gets displaced through opposing jet to point $A$. Point $\mathrm{A}$ is the new stagnation point lying on the interface curve between disturbed shock wave and Mach disc of jet. Point $C$ represent the pressure value of the jet at the leading edge of an airfoil that is significantly higher than the free stream total pressure. 


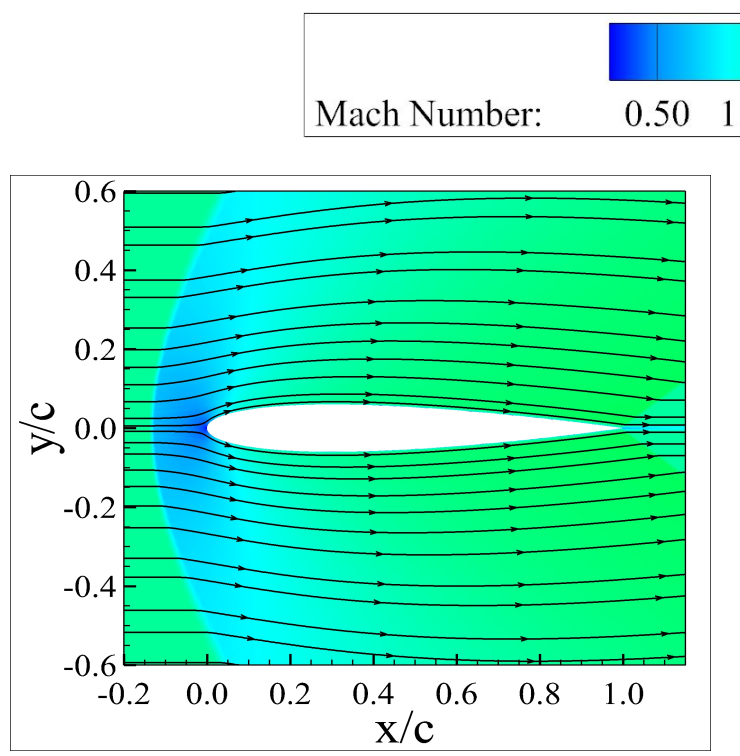

(a) Without jet

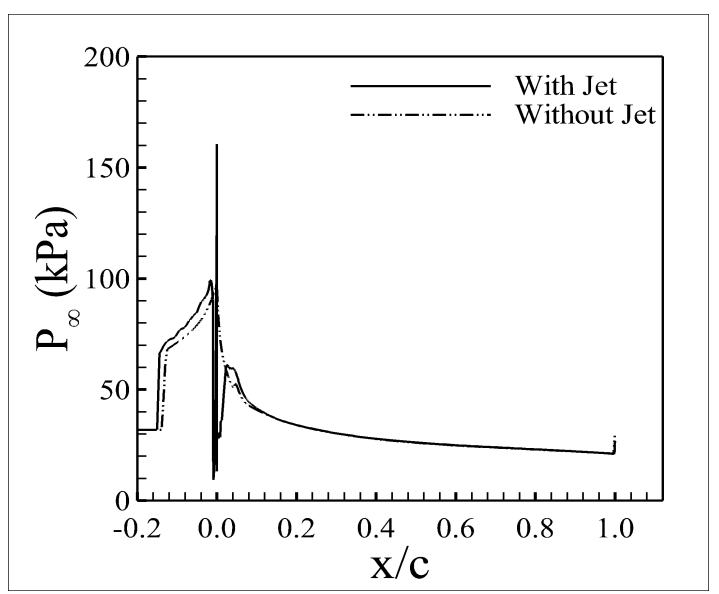

(c) Pressure distribution at upper surface (leading to trailing edge) of airfoil

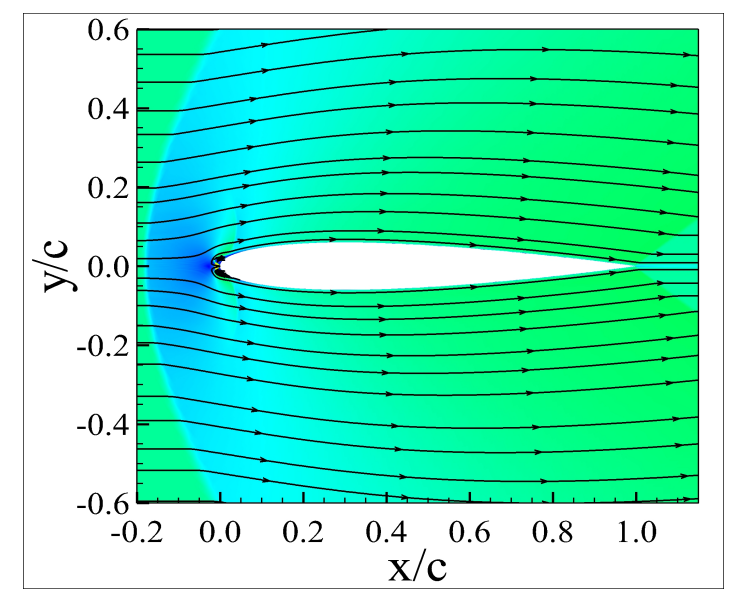

(b) With jet

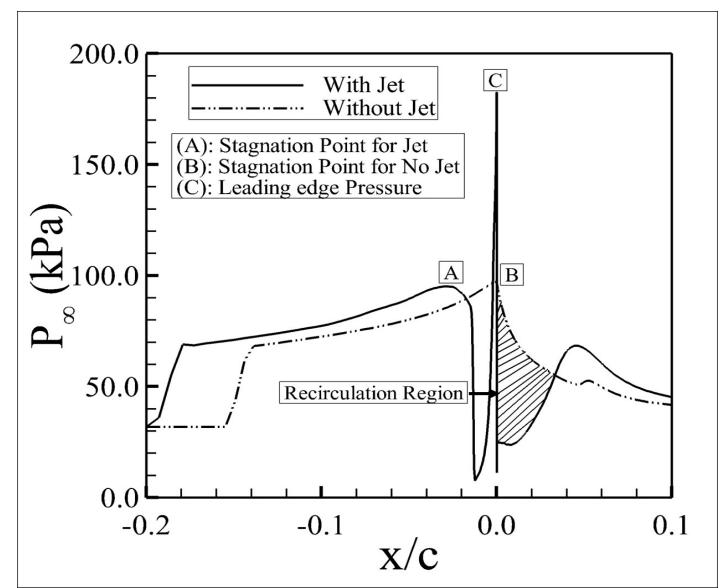

(d) Decrease in pressure due to recirculation regions

Figure 9. The comparison of drag reduction due to formation of recirculation regions.

The modes are shown in Figure 10a-1. For $P R=0.8$, the total pressure in the jet reservoir is less than the stagnation pressure. Therefore, the jet ejection from the orifice do not take place. However, when $P R$ is greater than one, the shock standoff distance amplifies with $P R$. Moreover, the flow pattern of re-circulation zone in the vicinity of opposing jet is also significantly changed. The distinct LPM mode can be seen at $P R$ of 1.9 and 2.4. The oscillatory behavior of pressure can be observed at these values. In LPM, the drag value is recorded enough due to the fluctuations that formulate a series of expansion and compression waves [19] at $P R=2.4$ (as in Figure 10f). The pressure of re-circulation regions were significantly higher than the stagnation point in front of Mach disc. From $P R$ of 2.8 and 3.0 onwards, a strong SPM mode is captured. The influence of opposing jet diminishes beyond $10 \%$ of the chord length $(x / c=0.1)$ as depicted in Figure 10a-1.

Similarly, some minor fluctuations were observed for SPM at $P R=3$ where pressure of re-circulation region was less than the stagnation point at different $P R$ values. 


\section{\begin{tabular}{|l|l|l|l|l|l|l|l|l|l|l|}
\hline & & & \\
\hline
\end{tabular} \\ $\begin{array}{lllllll}\text { Mach Number: } \quad 0.50 & 1.00 & 1.50 & 2.00 & 2.50 & 3.00\end{array}$}

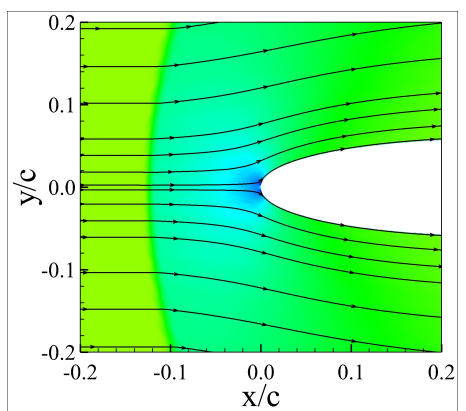

(a) $P R=0.8$

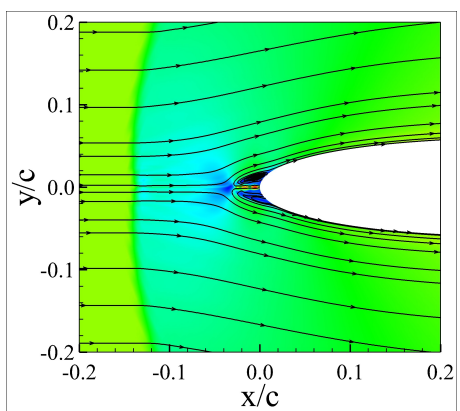

(b) $P R=1.9$

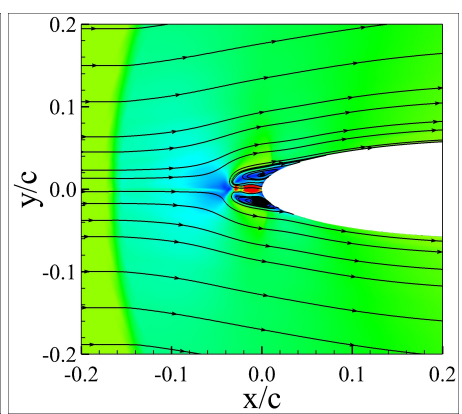

(c) $P R=2.4$

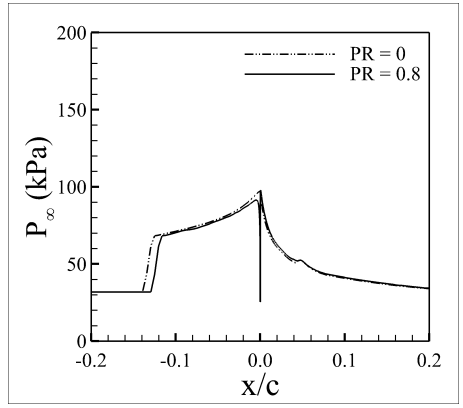

(d) $P R=0.8$

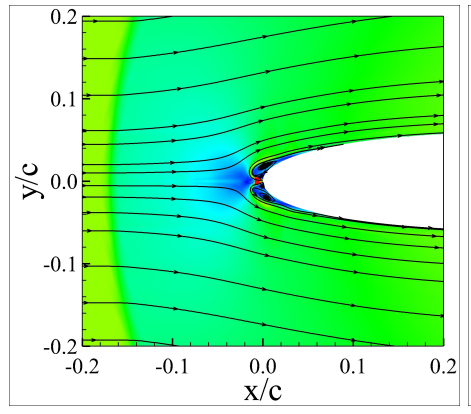

(g) $P R=2.8$

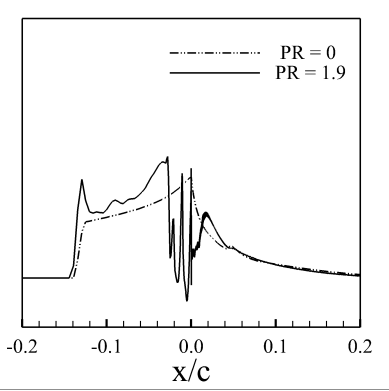

(e) $P R=1.9$

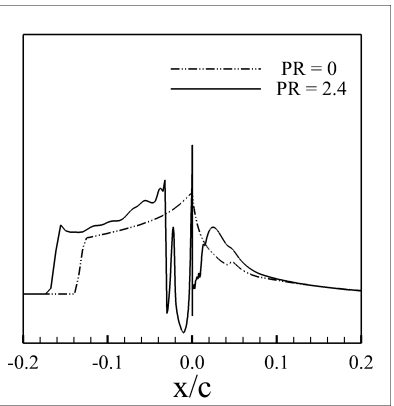

(f) $P R=2.4$

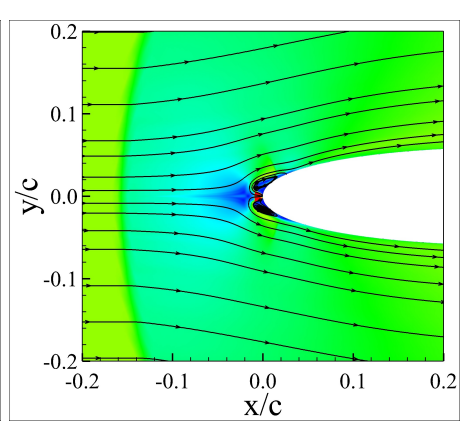

(h) $P R=3.0$

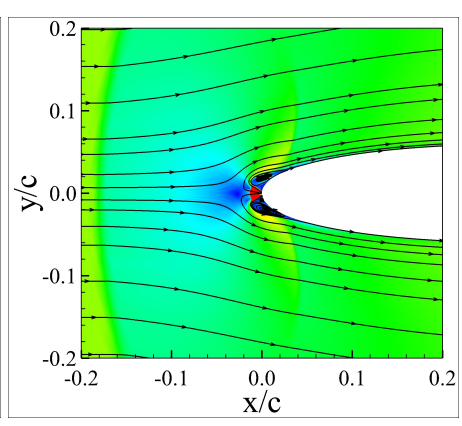

(i) $P R=4.0$

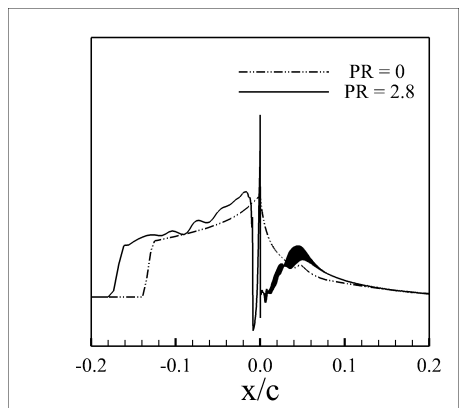

(j) $P R=2.8$

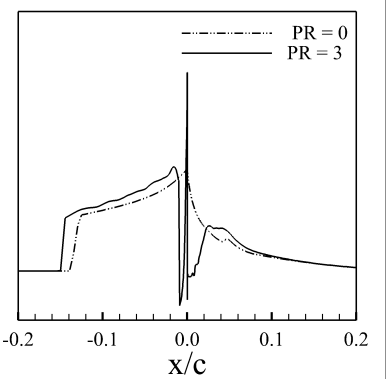

(k) $P R=3.0$

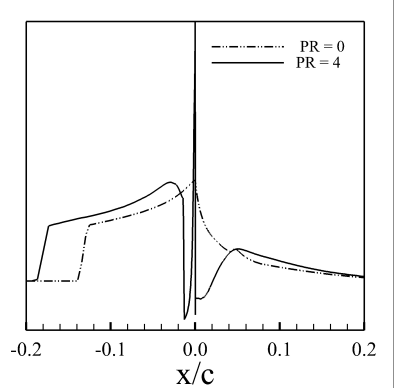

(1) $P R=4.0$

Figure 10. The pressure distribution of free stream flow at constant $M_{\infty}=1.4$ and increasing $P R$ between 0.8 to 4.0 .

As the free-stream static pressure at the interface curve was greater than the counter flow jet, the stagnation point of interface stopped Mach disc of jet from further protrusion. With the increase 
in PR value, the Mach disc also got enlarged thereby bending the barrel shocks. The bending of shockwaves along the free-stream flow also moved the re-circulation regions over the airfoil surface. That re-circulation region creates an imaginary body that reduces the skin friction coefficient from the leading edge of airfoil. Figure 11a empirically illustrate the flow field difference between no jet, unsteady LPM and steady SPM modes. The flow manifests the same trend as that of Rebecca [48] who analyzed the flow modes on blunt body at free stream Mach 3.48. There is a transition region that coexists between LPM and SPM modes. At $P R=4$, the Mach disc does not maintain its shape as depicted in Figure 11b. The increment in $P R$ increases the mass flow rate [8].

The increase in mass flow rate on small jet to body diameter ratio build more under-expanded jet and less jet stream passes through the barrel shock [49]. Same can be observed in Figure 11b where the increase in mass flow rate by increasing pressure ratio $(P R=4)$, due to the formation of relatively compressed barrel shock offers more room to the jet's out flow as compared to the lower pressure ratio $(P R=3)$. Location of Mach Disk for different pressure ratios can be controlled by varying jet diameter.

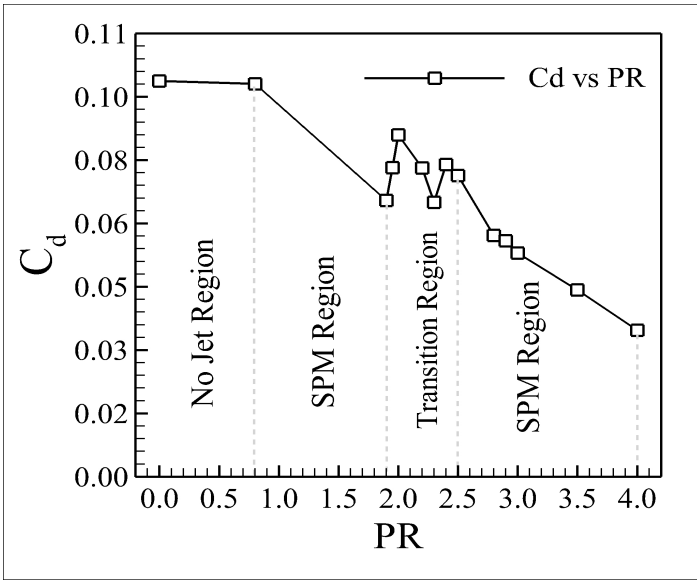

(a) Regional distribution of Flow modes.

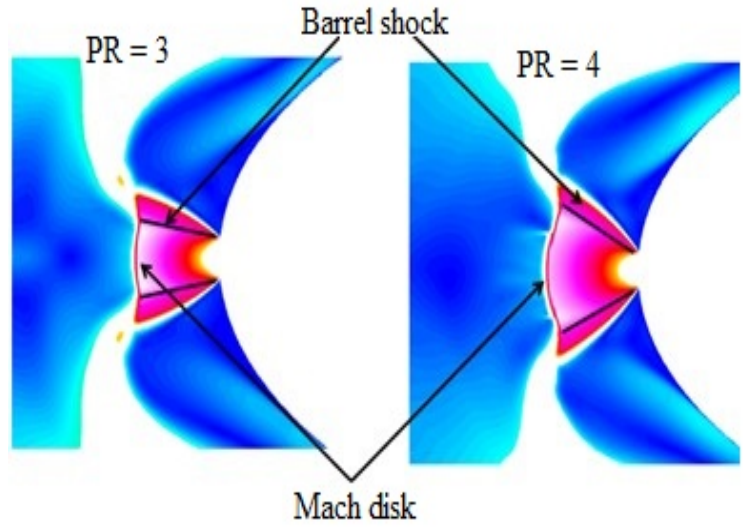

(b) Movment of barrel shockwave due to change in $P R$ value.

Figure 11. Under-expansion of opposing jet at different pressure ratio and its regional distribution.

\subsection{Angle of Attack}

The comparison of instantaneous pressure distributions for no jet and jet cases at various angles of attack are illustrated in Figure 12a-d. Flow conditions used for counter flow jet are $P R=3, M \infty=1.4$ $\& M_{j}=1$. The position of shock collides with the stagnation point that indicates a potential increase in drag for no jet case. By the utilization of counter flow jet, the shock standoff distance increases which alleviate the drag effect with the increase in angle of attack.

SPM mode remains steady and stable with the increase in angle of attack $\left(\alpha_{\infty}\right)$. By increasing $\alpha_{\infty}$ from $0^{\circ}$ to $6^{\circ}$, the flow structure of SPM sustained as depicted in Figure 12a-d, though a strong flow asymmetry was introduced at higher values. This asymmetry persists and apparently becomes stronger with increasing angles of attack $\left(8^{\circ}\right.$ and $\left.10^{\circ}\right)$ until the counter flowing jet cannot persist the short penetration state. The counter flow jet was detected in one side of an airfoil and shock wave reattached with the surface. The comparison of pressure graphs of with and without jet (Figure 12a-d) reinforces the above explanation. 


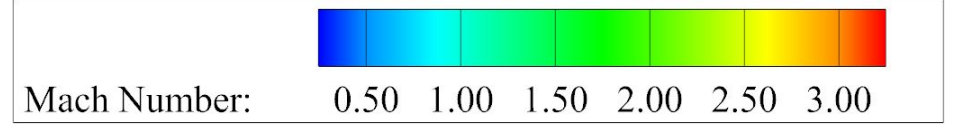
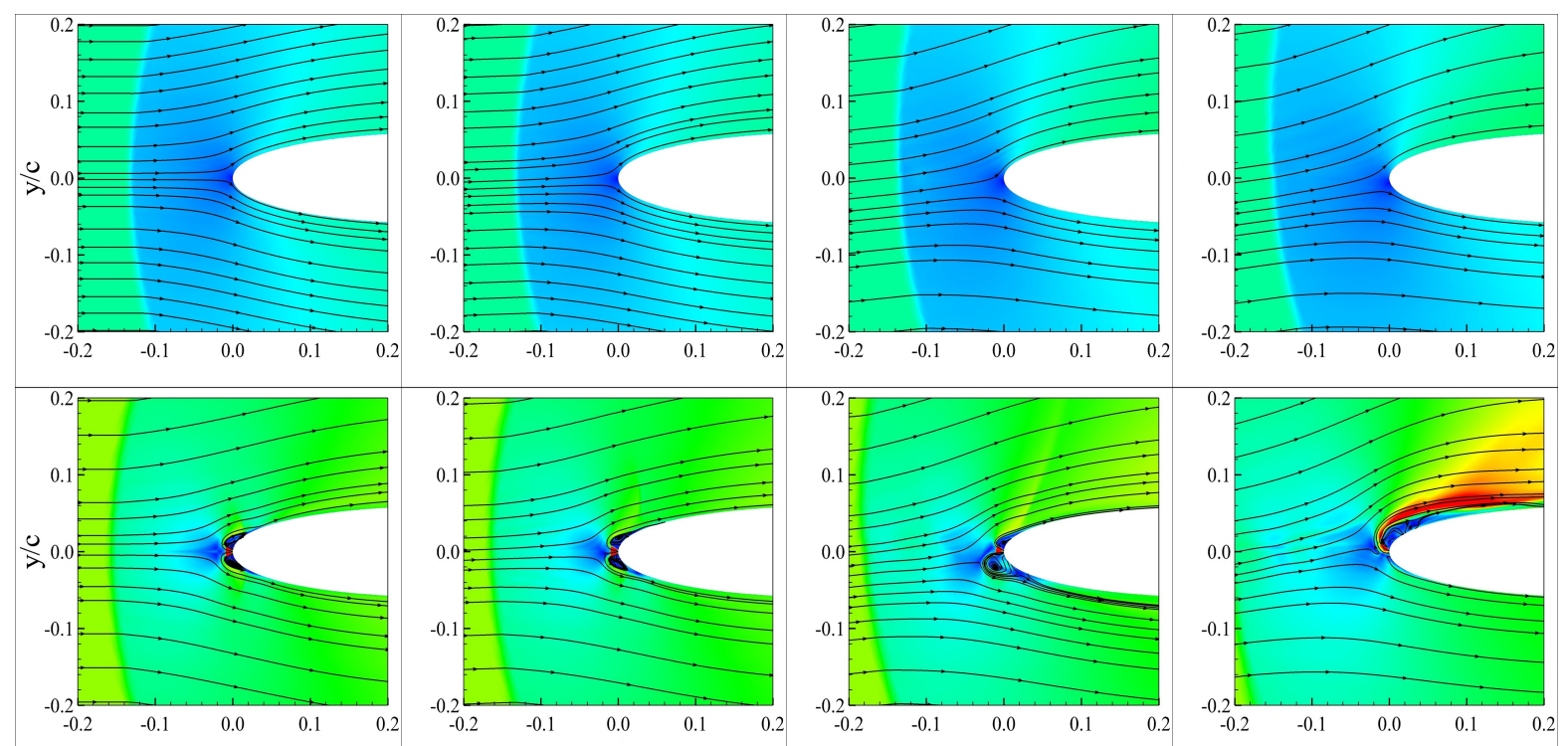

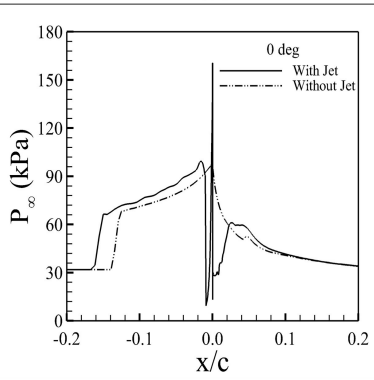

(a) $\alpha=0^{\circ}$

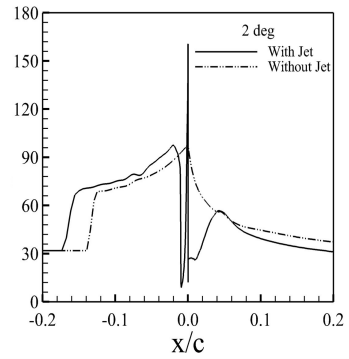

(b) $\alpha=2^{\circ}$

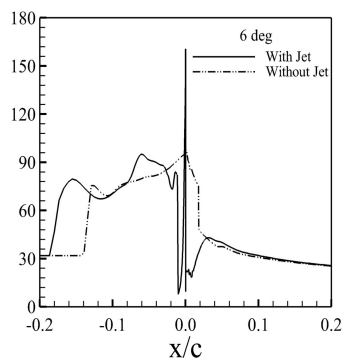

(c) $\alpha=6^{\circ}$

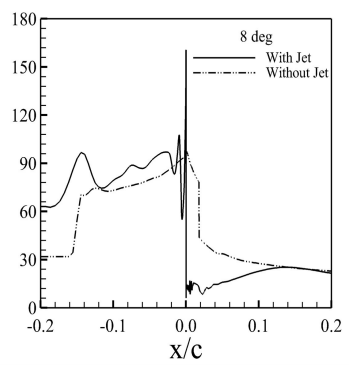

(d) $\alpha=8^{\circ}$

Figure 12. Pressure distribution of free stream flow with increasing angles of attack $\left(\alpha=0^{\circ}\right.$ to $\left.8^{\circ}\right)$ at constant $P R=3.0$ and $M_{\infty}=1.4$.

\section{Aerodynamic Performance and Stability Analysis}

The aerodynamic efficiency (lift-to-drag ratio) increases with the increase in angle of attack and maximizes till $8^{\circ}$. The advantage of reduction in coefficient of drag reduces with the increase in angle of attack as shown in Figure 13b. The overall performance of airfoil increases by using counter flow jet as depicted from Figure 13a. The re-circulation regions tilt in the windward direction and fill the wake areas of airfoil at higher angles of attack. It is evident from the Figure 13a that after the stall of an airfoil, the performance of jet is no longer as efficient as it is for lower angles of attack.

Figure 14a show the comparison of lift coefficients of with and without cases at range of angles of attack $\left(\alpha=0^{\circ}-8^{\circ}\right)$. It is evident from Figure 14a that by implementing jet the lift increases, drag reduces and static stability remains unchanged at positive angles of attack (Figure 14b).

The opposing jet certainly influence stability parameters as well. These stability parameters were calculated at constant free stream Mach 1.4 for both with and without jet cases with a pivot point at mid $(0.5 c)$ of chord of airfoil. The equation of linear line is assumed analogously for the calculation of static stability derivatives.

$$
y=m x+c
$$

however, $m$ is the slope of linear line. The adopted analogy for the hysteresis loops of pitching moment coefficient $\left(C_{m}\right)$ is changing as

$$
y=C_{i_{j}} x+C_{i_{0}}
$$


whereas, $i$ and $j$ represents the moment $(m)$ and angle of attack $(\alpha)$ of perturbed airfoil. So, the equation 13 becomes

$$
y=C_{m_{\alpha}} x+C_{m_{0}}
$$

and $C_{m_{\alpha}}$ is the pitching moment slope coefficient of hysteresis loops. To evaluate dynamic stability derivatives, fully converged static cases were initialized with forced oscillations.

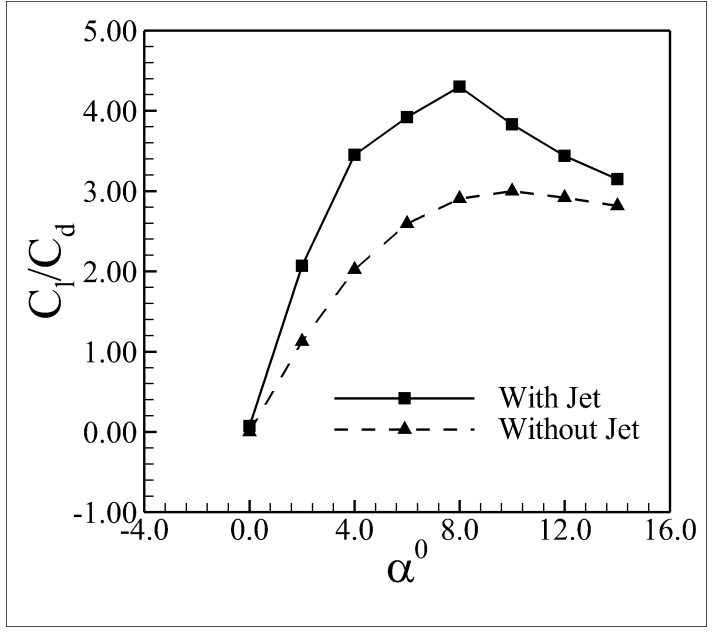

(a) Effects of opposing jet on the aerodynamic efficiency of airfoil

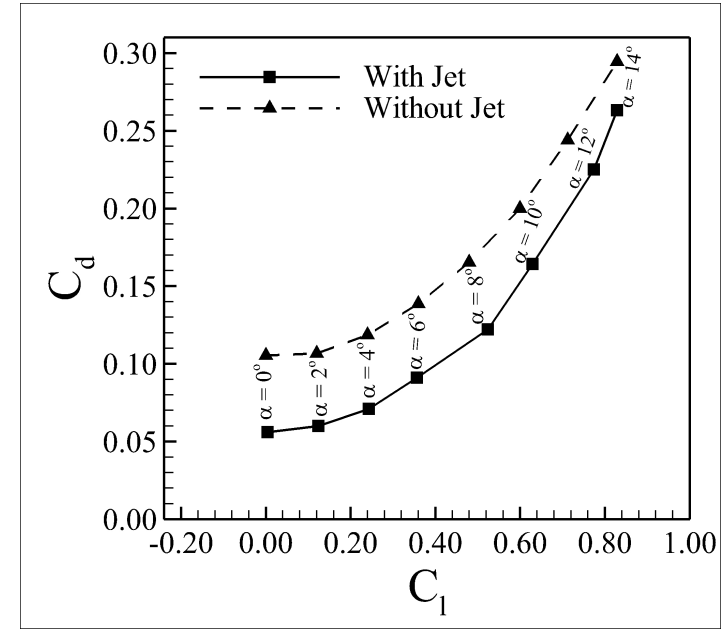

(b) Decrease in the drag polar of airfoil

Figure 13. Effects of opposing jet by increasing the $\alpha$.

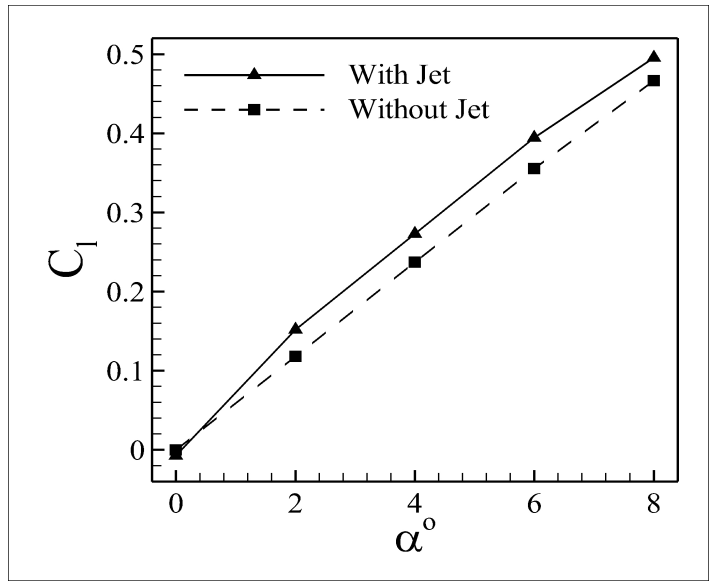

(a)

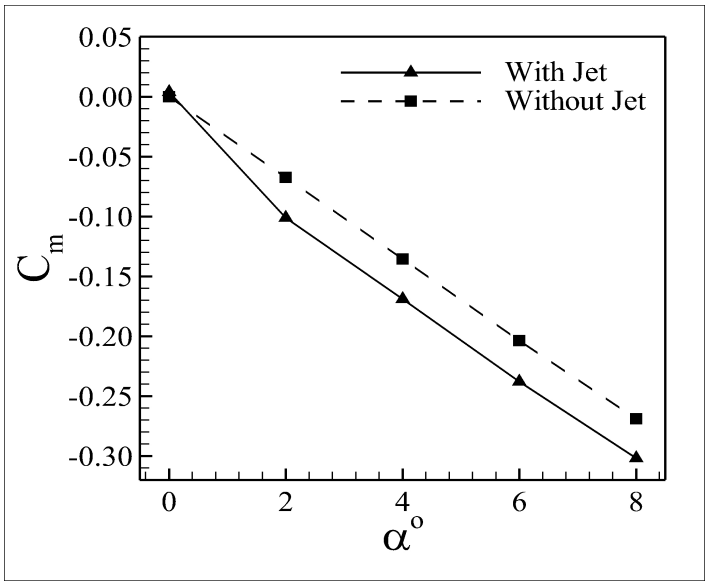

(b)

Figure 14. Effects of opposing jet on the lift and moment coefficients of airfoil by increasing the static angles of attack $\left(\alpha=0^{\circ}\right.$ to $\left.8^{\circ}\right)$.

The sensitivity of dynamic stability derivatives is checked against reduced frequency, mean angle of attack and amplitude of forced oscillations. The reduced frequency contributes a lot in the longitudinal pitch damping derivatives. The dynamic derivatives of with and without opposing jet are shown in Figure 15a,b for several values of reduced frequencies with constant amplitude $\alpha_{A}=4^{\circ}$. Figure 15a shows that by increasing reduced frequency the body moves towards the unstable behavior (The value of $\left(C_{m_{q}}+C_{m_{\dot{\alpha}}}\right)$ start increasing). Although it shows a linear behavior along increasing angles of attack. But in the case of ejection of jet these linear behaviors drastically change for low frequencies $(k=0.05,0.1)$. However, for higher frequencies in opposing jet shows linear behavior for increasing angles of attack as it was for no jet case. 


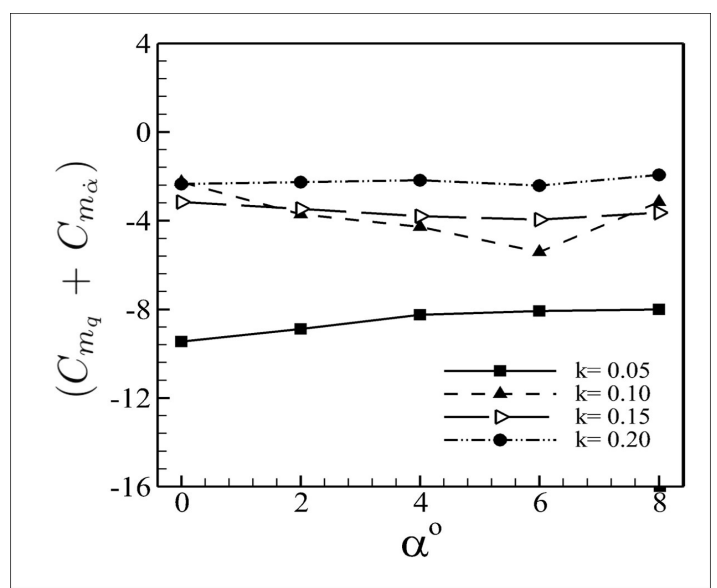

(a) Without jet

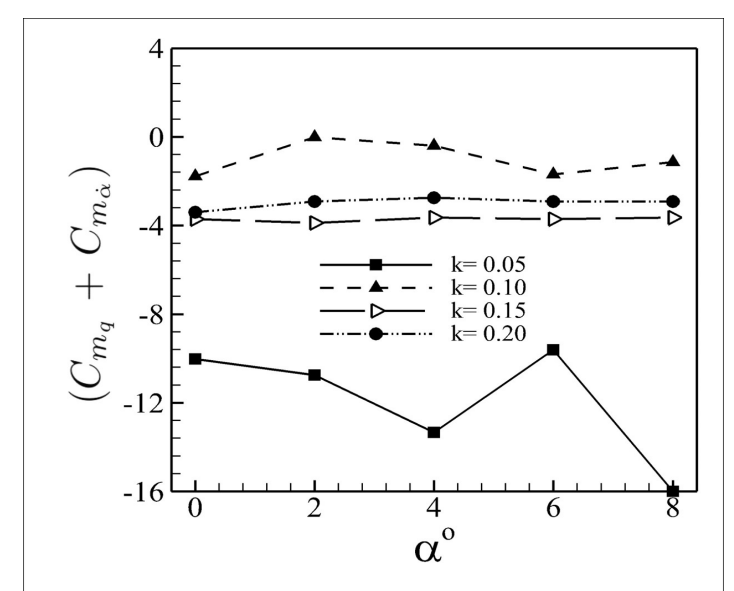

(b) With jet

Figure 15. Effects of reduced frequency on the pitch damping of airfoil with constant $\alpha_{o}=0^{\circ}$ and $\alpha_{A}=4^{\circ}$.

Basically, there are three types of bodies (primary, secondary and tertiary) that affect the moment coefficient and its damping forces as shown in Figure 15a,b. The most important body is the primary body that is an airfoil. As the angles of attack starts increasing from $0^{\circ}$ the secondary body (generation of adverse pressure gradient) starts developing and effects on the overall moment coefficient $C_{m}$. This adverse pressure gradient (secondary body) brings stall for the body at high angles of attack.

But in case of jet ejection, a jet with recirculation regions represents a third body (tertiary body) generated which reduces drag from the leading edge of an airfoil but also effects the stability derivatives. At low angles of attack, no secondary body is present for low reduced frequency $(k=0.05)$, but the tertiary body (jet with recirculation regions) still produce effects on the stability derivatives as shown in Figure $15 b$.

The comparison of without and with jet cases at $k=0.05$ shows that the without jet case depicts linear trend whereas the nonlinearity produces for increasing angles of attack by the ejection of jet. As clear from above Figure $12 \mathrm{a}-\mathrm{d}$, by increasing angles the jet disturbed from the leading edge causes instability in flow which leads the disturbance in the dynamic stability parameters as illustrated in Figure 15b. By increasing the reduced frequency, a similar linear trend starts building for higher angles of attack as that of without ejection of jet. The reason behind this linearity is reduction of opposing jet (tertiary body) effectiveness on the movement of the airfoil (primary body) but the secondary body (adverse pressure gradient) still exists as they were for without opposing jet.

The other parameter of interest is the influence of the angles of attack on the stability derivatives. The analysis was carried out at several angles of attack $\left(\alpha_{o}=0^{\circ}, 2^{\circ}, 4^{\circ}, 6^{\circ} \& 8^{\circ}\right)$ with fixed amplitude of $4^{\circ}$ and reduced frequency of 0.2. By the application of jet, the slope of stability derivatives is damped as compared to without jet cases (Figure 16a,b). With increasing angles of attack, a negative slope starts developing for pitching moment of simple perturbed airfoil (as shown in Figure 16a), while the ejection of opposing jet from the leading edge leads the negative slope towards the positivity as depicts in Figure 16b. At higher angle $\left(8^{\circ}\right)$ the effect of opposing jet starts reducing (or vanished) which leads the positive slope towards the negative value.

The number of calculations was made to investigate the influence of mean angles of attack on airfoil stability. The analysis were carried out at several mean angles of attack $\left(\alpha_{o}=0^{\circ}, 2^{\circ}, 4^{\circ}, 6^{\circ} \& 8^{\circ}\right)$ with fixed reduced frequency $k=0.2$ at mid chord movement. In this analysis the amplitude of motion was also varied and selected as, $\alpha_{A}=2^{\circ}, 4^{\circ}, 6^{\circ} \& 8^{\circ}$.

The comparison in Figure 17a,b shows that by implementing jet on the stagnation point of an airfoil the dynamic stability enhances. It was noticed that for jet case the pitch damping derivatives decreases as the angle of attack increases. But beyond the mean angle $6^{\circ}$ the dynamic pitch coefficient 
value starts increasing again because at higher mean angle the recirculation regions of jet attached to the free stream flow and destroyed the jet mode, so the value of $C_{m_{q}}+C_{m_{\dot{\alpha}}}$ starts increasing and reached close to the without jet case.

The reduction at the lower angles are due to the abrupt decrease in the pressure on the upper surface at windward side as shown in Figure 18a-c. This reduction brings the restoring moment in the dynamic system of airfoil, which ultimately decreases the overall dynamic derivatives of stability at lower angles of attack. The positive coefficient of pressure distribution of leading edge is reduced with the ejection of jet. The vicinity on the upper surface contributes a destabilizing to damping coefficient that suppress with introduction of jet.

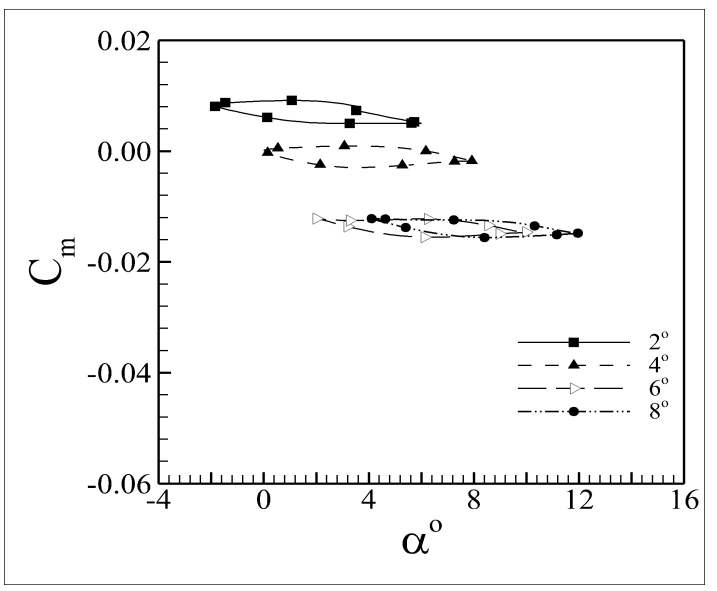

(a) Without jet

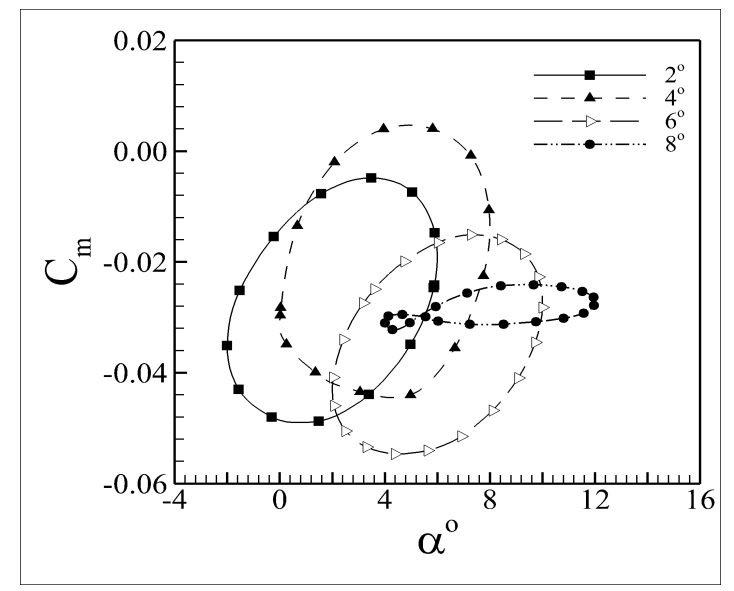

(b) With jet

Figure 16. Comparison of pitch moment coefficient $C_{m}$ for $\alpha_{o}=2^{\circ}$ to $8^{\circ}$ with constant amplitude $\left(\alpha_{A}=4^{\circ}\right)$.

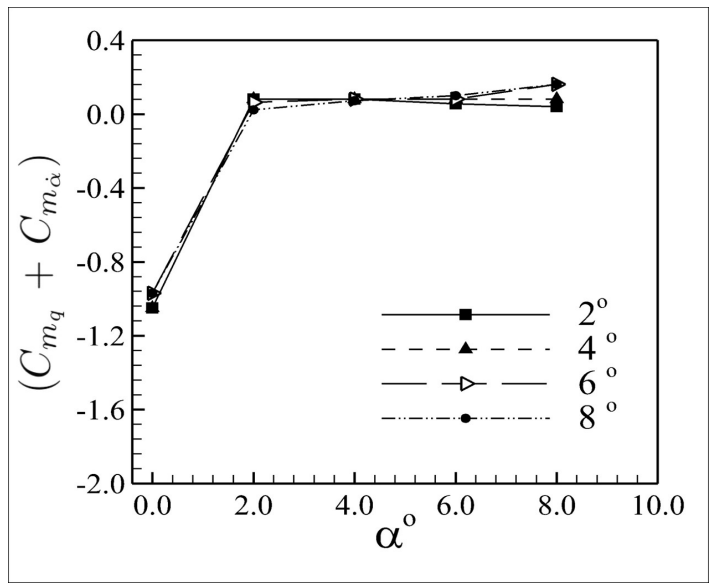

(a) Without jet

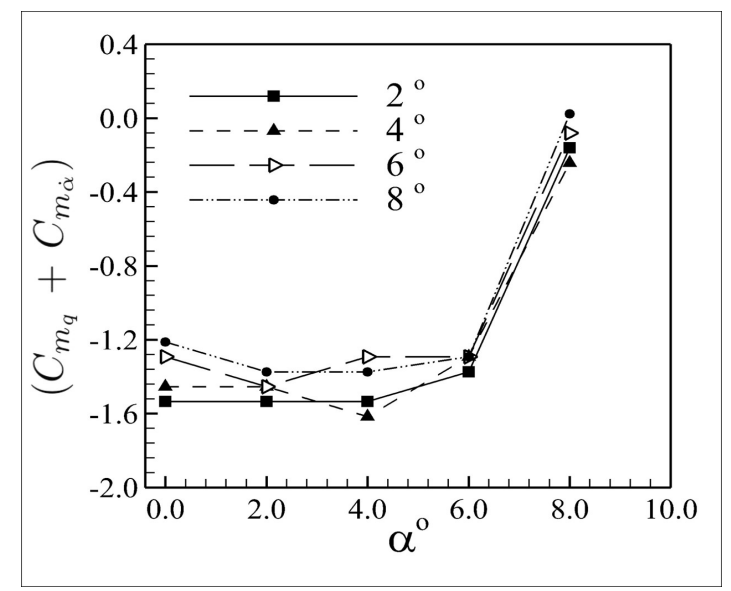

(b) With jet

Figure 17. Effects of opposing jet on the dynamic pitching coefficient $\left(C_{m_{q}}+C_{m_{\dot{\alpha}}}\right)$ airfoil with constant $P R=3, M_{j}=1$ and $M_{\infty}=1.4$. 


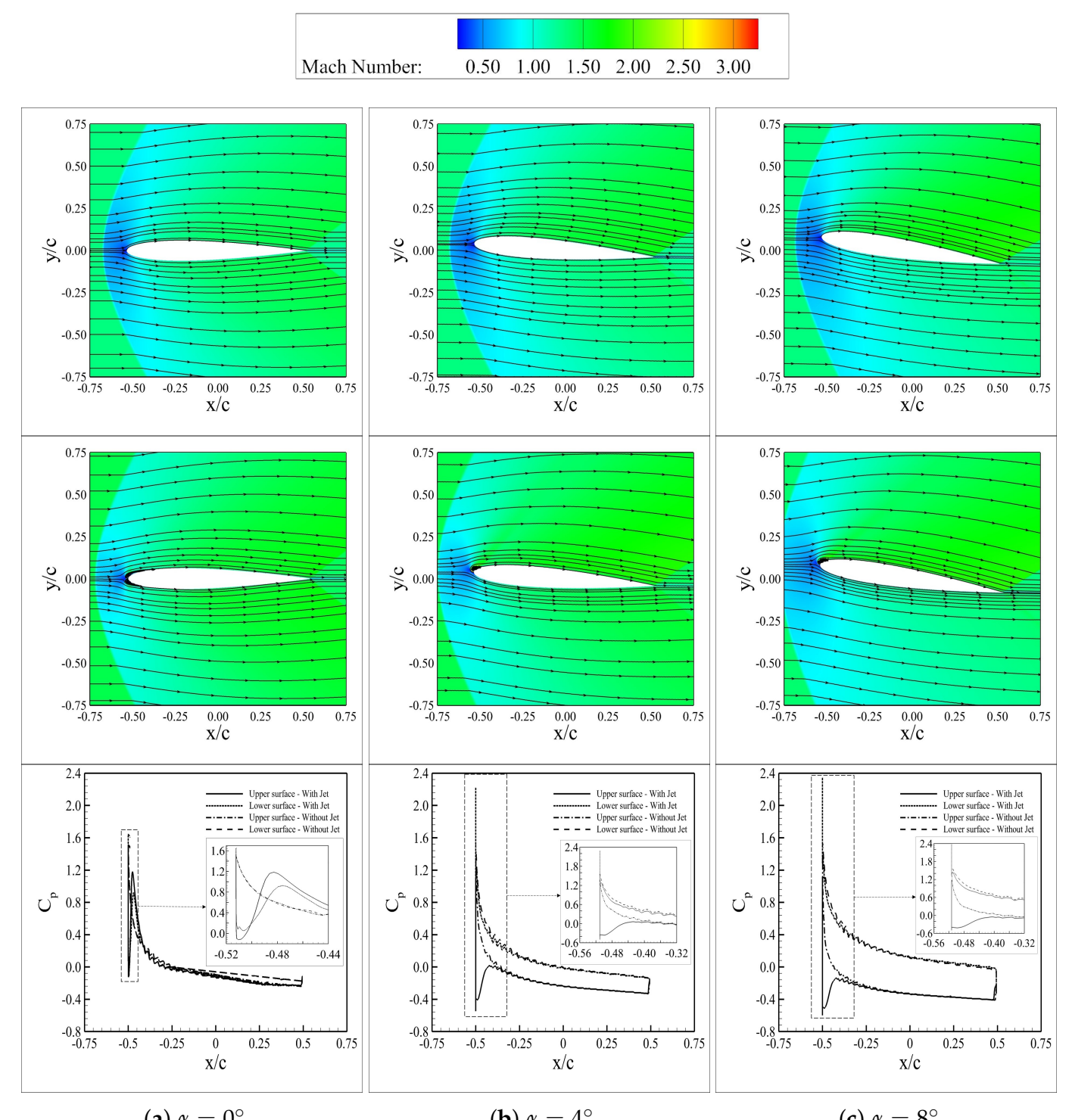

(a) $\alpha=0^{\circ}$

(b) $\alpha=4^{\circ}$

(c) $\alpha=8^{\circ}$

Figure 18. Variation of free stream pressure distribution by changing the airfoil angles of attack dynamically $\left(\alpha=0^{\circ}\right.$ to $\left.8^{\circ}\right)$ using UDF, at constant amplitude of airfoil $\left(\alpha_{A}=4^{\circ}\right)$ and flow mean angle of attack $\left(\alpha=4^{\circ}\right)$.

\section{Conclusions}

The current numerical research aimed to understand the phenomenon of opposing jet for drag reduction on a blunt leading edge airfoil (however, discussion related to temperature, density and acoustic were not considered for the analysis of opposing jet). After the numerical validation of baseline experimental cases, a jet is introduced on conventional airfoil. The computational investigation shows that by introducing opposing jet the overall drag of an airfoil reduces up to $70 \%$. However, the performance of supersonic jet is extremely affected by varying operating parameters as follows:

- The pressure ratio $(P R)$ is the key parameter that affects the counter flow jet. The LPM exists in a smaller range of pressure ratios (2.4); it produces a long shock standoff distance. As the pressure ratio is beyond the threshold value, the counter flow jet transmits its flow variation from LPM to $\operatorname{SPM}(P R=3)$.

- Increased in angles of attack influenced the opposing jet efficiency. Beyond $\alpha_{\infty}=6$, the jet destroyed and the drag at the leading edge starts increasing again. 
- Free stream Mach is the major influencing parameter. The SPM mode is achieved at $M=2$. With further increase in Mach $(M=3)$ the jet becomes highly under expanded and the shape of the Mach disc changes into a convex form.

- The static and dynamic stability of airfoil in supersonic flow enhances by the implementation of jet. At higher free stream flow angles $\left(\alpha_{\infty}=6\right)$ the jet does not work properly as it tilts in the free stream flow direction. So, the stability of an airfoil reduced.

Author Contributions: Conceptualization, S.R., F.N. and A.M.; S.R. and F.N. performed the investigation and numerical analysis; Supervision, A.M.; Writing-Original Draft, S.R., F.N.; Writing-Review Editing, A.M., R.R. and S.S. All authors have read and agree to the published version of the manuscript.

Funding: There were no funding sources for this research.

Acknowledgments: We acknowledge, Laurent Dala for providing us the basic theme of opposing jet technique and RCMS for high performance computing facility.

Conflicts of Interest: The authors declare no conflict of interest.

\section{References}

1. Talay, T.A. Introduction to the Aerodynamics of Flight; Scientific and Technical Information Office, National Aeronautics and Space: Washington, DC, USA, 1975; Volume 367.

2. McLean, F.E. Supersonic Cruise Technology; NASA SP-472; NASA Special Publication: Washington, DC, USA, 1985; pp. 472-473.

3. Bushnell, D.M. Shock wave drag reduction. Annu. Rev. Fluid Mech. 2004, 36, 81-96. [CrossRef]

4. Watts, G.A. An Experimental Investigation of a Sonic Jet Directed Upstream against a Uniform Supersonic Flow; Institute of Aerophysics, University of Toronto TN7: Toronto, ON, Canada, 1956.

5. Love, E.S. The Effects of a Small Jet of Air Exhausting from the Nose of a Body of Revolution in Supersonic Flow; NACA RM L52119a; NACA: Boston, MA, USA, 1952.

6. Qu, F.; Sun, D.; Bai, J.; Zuo, G.; Yan, C. Numerical investigation of blunt body's heating load reduction with combination of spike and opposing jet. Int. J. Heat Mass Transf. 2018, 127, 7-15. [CrossRef]

7. Huang, W.; Yan, L. Progress in research on mixing techniques for transverse injection flow fields in supersonic crossflows. J. Zhejiang Univ. Sci. A 2013, 14, 554-564. [CrossRef]

8. Shen, B.; Liu, W.; Yin, L. Drag and heat reduction efficiency research on opposing jet in supersonic flows. Aerosp. Sci. Technol. 2018, 77, 696-703. [CrossRef]

9. Baron, J.R.; Alzner, E. An experimental investigation of a two-layer inviscid shock cap due to blunt-body nose injection. J. Fluid Mech. 1963, 15, 442-448. [CrossRef]

10. Warren, C.; Hugh, E. An experimental investigation of the effect of ejecting a coolant gas at the nose of a bluff body. J. Fluid Mech. 1960, 8, 400-417. [CrossRef]

11. Gerdroodbary, M.B.; Bishehsari, S.; Hosseinalipour, S.M.; Sedighi, K. Transient analysis of counterflowing jet over highly blunt cone in hypersonic flow. Acta Astronaut. 2012, 73, 38-48. [CrossRef]

12. Daso, E.O.; Pritchett, V.E.; Wang, T.-S.; Ota, D.K.; Blankson, I.M.; Auslender, A.H. Dynamics of shock dispersion and interactions in supersonic freestreams with counterflowing jets. AIAA J. 2009, 47, 1313-1326. [CrossRef]

13. Romeo, D.J.; Sterrett, J.R. Flow field for sonic jet exhausting counter to a hypersonic mainstream. AIAA J. 1965, 3, 544-546. [CrossRef]

14. Jarvinen, P.O.; Adams, R.H. The Effects of Retrorockets on the Aerodynamic Characteristics of Conical Aeroshell Planetary Entry Vehicles; AIAA Paper 70-219; AIAA: Reston, VA, USA, 1970.

15. Deng, F.; Xie, F.; Qin, N.; Huang, W.; Wang, L.; Chu, H. Drag reduction investigation for hypersonic lifting-body vehicles with aerospike and long penetration mode counterflowing jet. Aerosp. Sci. Technol. 2018, 76, 361-373. [CrossRef]

16. Hayashi, K.; Aso, S.; Tani, Y. Numerical study on aerodynamic heating reduction by opposing jet. AIAA J. 2006, 1, 66 .

17. Bibi, A.; Maqsood, A.; Sherbaz, S.; Dala, L. Drag reduction of supersonic blunt bodies using opposing jet and nozzle geometric variations. Aerosp. Sci. Technol. 2017, 69, 244-256. [CrossRef] 
18. Li, S.; Wang, Z.; Huang, W.; Liu, J. Effect of the injector configuration for opposing jet on the drag and heat reduction. Aerosp. Sci. Technol. 2016, 51, 78-86. [CrossRef]

19. Yisheng, R. Drag reduction research in supersonic flow with opposing jet. Acta Astronaut. 2013, 91, 1-7. [CrossRef]

20. Finley, P.J. The flow of a jet from a body opposing a supersonic free stream. J. Fluid Mech. 1966, 26, 337-368. [CrossRef]

21. Woods, W.C.; Jones, K.M.; Genzel, N.N. Preliminary Investigation of Stagnation Point Liquid Injection Influence on Blunt Body Aerodynamics; AIAA: Reston, VA, USA, 2002.

22. Barber, E.A. An experimental investigation of stagnation-point injection. J. Spacecr. Rocket. 1965, 2, 770-774. [CrossRef]

23. Pish, F.; Moradi, R.; Edalatpour, A.; Gerdroodbary, M.B. The effect of coolant injection from the tip of spike on aerodynamic heating of nose cone at supersonic flow. Acta Astronaut. 2019, 154, 52-60. [CrossRef]

24. Gerdroodbary, M.B.; Imani, M.; Ganji, D.D. Heat reduction using conterflowing jet for a nose cone with aerodisk in hypersonic flow. Aerosp. Sci. Technol. 2014, 39, 652-665. [CrossRef]

25. Fomin, V.M.; Maslov, A.A.; Shashkin, A.P.; Korotaeva, T.A.; Malmuth, N.D. Flow regimes formed by a counterflow jet in a supersonic flow. J. Appl. Mech. Tech. Phys. 2001, 42,757-764. [CrossRef]

26. Ou, M.; Yan, L.; Huang, W.; Li, S.; Li, L. Detailed parametric investigations on drag and heat flux reduction induced by a combinational spike and opposing jet concept in hypersonic flows. Int. J. Heat Mass Transf. 2018, 126, 10-31. [CrossRef]

27. Lu, H.; Liu, W. Investigation of thermal protection system by forward-facing cavity and opposing jet combinatorial configuration. Chin. J. Aeronaut. 2013, 26, 287-293. [CrossRef]

28. Huang, W.; Yan, L.; Liu, J.; Jin, L.; Tan, J. Drag and heat reduction mechanism in the combinational opposing jet and acoustic cavity concept for hypersonic vehicles. Chin. J. Aeronaut. 2015, 42, 407-414. [CrossRef]

29. Ou, M.; Yan, L.; Huang, W.; Zhang, T. Design exploration of combinational spike and opposing jet concept in hypersonic flows based on CFD calculation and surrogate model. Acta Astronaut. 2019, 155, 287-301. [CrossRef]

30. Shantz, I.; Groves, R.T. Dynamic and Static Stability Measurements of the Basic Finner at Supersonic Speeds; Tech. rep.; Naval Ordnance Lab: White Oak, MD, USA, 1960.

31. MacAllister, L.C.The Aerodynamic Properties of a Simple Non Rolling Finned Cone-Cylinder Configuration Between Mach Numbers 1.0 and 2.5; Tech. rep.; Army Ballistic Research Lab: Aberdeen Proving Ground, MD, USA, 1955.

32. Winchenbach, G.L.; Uselton, R.L.; Hathaway, W.H.; Chelekis, R.M. Free-flight and wind-tunnel data for a generic fighter configuration. J. Aircr. 1984, 21, 5-13. [CrossRef]

33. Uselton, B.L. A Description of the Standard Dynamic Model (SDM); Technical Report, 56th STA Meeting; MIT: Cambridge, MA, USA, 1981.

34. Alemdaroglu, N.; Iyigun, I.; Altun, M.; Uysal, H.; Quagliotti, F.; Guglieri, G. Determination of dynamic stability derivatives using forced oscillation technique. In Proceedings of the 40th AIAA Aerospace Sciences Meeting \& Exhibit, Reno, Nevada, 14-17 January 2002; p. 528.

35. Davari, A.R.; Soltani, M.R. Effects of plunging motion on unsteady aerodynamic behavior of an aircraft model in compressible flow. Iranian J. Sci. Technol. 2007, 31, 49.

36. Schmidt, E. Standard Dynamics Model Experiments with the DFVLR/AVA Transonic Derivative Balance. In Proceedings of the AGARD CP-386 Unsteady Aerodynamic-Fundamentals and Applications to Aircraft Dynamics, Gottingen, Germany, 6-9 May 1985.

37. Hall, R.; Biedron, R.; Ball, D.; Bogue, D.; Chung, J.; Green, B.; Grismer, M.; Brooks, G.; Chambers, J. Computational methods for stability and control (COMSAC): The time has come. In Proceedings of the AIAA Atmospheric Flight Mechanics Conference and Exhibit, San Francisco, California, 15-18 August 2005; p. 6121.

38. Murman, S.M. Reduced-frequency approach for calculating dynamic derivatives. AIAA J. 2007, 45, 1161-1168. [CrossRef]

39. Da Ronch, A.; Ghoreyshi, M.; Badcock, K.; Vallespin, D. Computation and evaluation of dynamic derivatives using CFD. In Proceedings of the 28th AIAA Applied Aerodynamics Conference, Chicago, IL, USA, 28 June-1 July 2010; p. 4817.

40. Itsariyapinyo, P.; Sharma, R.N. Large Eddy simulation of a NACA0015 circulation control airfoil using synthetic jets. Aerosp. Sci. Technol. 2018, 82, 545-556. [CrossRef] 
41. Graham, WJ. The Pressure-Drag due to Blunt Leading Edges on Two-Dimensional Aerofoils, at Transonic and Low-Supersonic Speeds; Aero Report 1151-A.R.C. 26 955; Her Majesty's Stationery Office: London, UK, 1965.

42. Landon, R.H.; Davis, S.S. Compendium of Unsteady Aerodynamic Measurements; Agard Rep No.702; AGARD: Paris, France, 1982.

43. Menter, F.R.; Menter, F.R. Two-equation eddy-viscosity turbulence models for engineering applications. AIAA J. 1994, 32, 1598-1605. [CrossRef]

44. Harris, C.D. Two-Dimensional Aerodynamic Characteristics of the NACA 0012 Airfoil in the Langley 8 Foot Transonic Pressure Tunnel; NASA TM 81927; NASA: Washington, DC, USA, 1981.

45. Tobak, M.; Schiff, L.B. Aerodynamic Mathematical Modeling-Basic Concepts; AGARD Lect. Ser. 114; AGARD: Paris, France, 1 March 1981.

46. Fujita, M. Axisymmetric oscillations of an opposing jet from a hemispherical nose. AIAA J. 1995, 33, 1850-1856. [CrossRef]

47. Huang, J.; Yao, W.; Jiang, Z. Penetration mode effect on thermal protection system by opposing jet. Acta Astronaut. 2019, 160, 206-215. [CrossRef]

48. Farr, R.; Chang, C.-L.; Jones, J.H.; Dougherty, N.S. On the comparison of the long penetration mode (LPM) supersonic counterflowing jet to the supersonic screech jet. In Proceedings of the 21st AIAA/CEAS Aeroacoustics Conference, Dallas, TX , 22-26 June 2015, p. 3126.

49. Tamada, I.; Aso, S.; Tani, Y. Numerical study of the effect of the opposing jet on reduction of aerodynamic heating with different nose configurations. In Proceedings of the 26th International Congress of the Aeronautical Sciences, Anchorage, AL, USA, 14-19 September 2008; pp. 14-19.

(C) 2019 by the authors. Licensee MDPI, Basel, Switzerland. This article is an open access article distributed under the terms and conditions of the Creative Commons Attribution (CC BY) license (http:/ / creativecommons.org/licenses/by/4.0/). 